Gerión. Revista de Historia Antigua

ISSN: 0213-0181

http://dx.doi.org/10.5209/geri.71946

\title{
Andrés Santos Samaniego y la epigrafía romana de Coria, Cáceres (Ms. 13.078 de la Biblioteca Nacional de España, Madrid) ${ }^{1}$
}

\author{
Enrique Paredes Martín ${ }^{2}$
}

Recibido: 27 de noviembre de 2019 / Aceptado: 17 de septiembre de 2020

Resumen: A mediados del siglo XVIII el erudito salmantino Andrés Santos Samaniego copió una serie de inscripciones romanas que localizó reutilizadas en las murallas de Coria (Cáceres), en lo que constituye la noticia más antigua que tenemos acerca de tales inscripciones. Aunque el interés de este autor no se centraba prioritariamente en la epigrafía romana de esta localidad, la importancia de los datos que aporta estriba en el hecho de que, para algunas inscripciones, constituyen no solo las primeras, sino las únicas informaciones relativas al respecto de sus características formales.

Palabras clave: Caurium; inscripciones latinas; epigrafía de Extremadura; inscripciones funerarias; tradición manuscrita; siglo XVIII.

\section{[en] Andrés Santos Samaniego and the Roman Epigraphy of Coria, Cáceres (Ms. 13.078, Biblioteca Nacional de España, Madrid)}

\begin{abstract}
In the middle of the $18^{\text {th }}$ century, the scholar Andrés Santos Samaniego, born in Salamanca, copied a series of Roman inscriptions that he found reused on the walls of Coria (Cáceres). His information constitutes the oldest news that we have about such inscriptions. Although this author's interest was not primarily focused on the Roman epigraphy of this locality, we will point out the value of the data that the author gives us about these inscriptions, because in some cases they can be considered as the first-and certainly, the only-information telling us the formal characteristics of these pieces.

Keywords: Caurium; Latin Inscriptions; Epigraphy of Extremadura; Funerary Inscriptions; Manuscript Transmission; $18^{\text {th }}$ century.

Sumario: 1. Breves notas sobre Andrés Santos Samaniego (Salamanca, ¿? - 1765) y el contexto de su obra. 2. La traditio sobre la epigrafía cauriense. 3. Las inscripciones recogidas por Santos Samaniego a la luz del Ms. 13.078 de la BNE. 3.1. Inscripción I. 3.2. Inscripción II. 3.3. Inscripción III. 3.4. Inscripción IV. 3.5. Inscripción V. 3.6. Inscripción VI. 4. Hübner, Guerra y Francisco de Coria. 5. A modo de conclusión. 6. Referencias bibliográficas.
\end{abstract}

1 Este trabajo ha sido realizado gracias a las Ayudas UCM para contratos predoctorales de Personal Investigador en Formación, Convocatoria 2017 CT17/17-CT18/17. Agradezco a los revisores anónimos sus consideraciones y sugerencias que, sin duda, han contribuido notablemente a mejorar y completar este trabajo; y muy especialmente a María del Rosario Hernando Sobrino por su inestimable ayuda en la búsqueda de fuentes y por su buen ojo epigráfico.

2 Universidad Complutense de Madrid - Archivo Epigráfico de Hispania.

E-mail: enripare@ucm.es

ORCID: 0000-0002-1347-9917 
Cómo citar: Paredes Martín, E. (2020): Andrés Santos Samaniego y la epigrafía romana de Coria, Cáceres (Ms. 13.078 de la Biblioteca Nacional de España, Madrid), en Gerión 38/2, 519-548.

\section{Breves notas sobre Andrés Santos Samaniego (Salamanca, i? - 1765) y el contexto de su obra}

Pese a la importante carrera académica y eclesiástica que desempeñó a lo largo de su vida, lo cierto es que no son muchos los datos concretos con que contamos al respecto de la vida y obra de Andrés Santos Samaniego quien, a veces, figura como Santos Calderón de la Barca, aludiendo al segundo apellido de su padre. Sabemos, no obstante, que nació en Salamanca en una fecha difícil de concretar en la primera mitad del siglo XVIII, siendo hijo de Petronila García de Samaniego y de Bernardo Santos Calderón de la Barca $(† 1744$, quien desempeñó, entre otros, los cargos de Fiscal de lo Civil de Barcelona, oidor y regente de Barcelona, fiscal del Consejo de Castilla o de ministro togado del Consejo de Castilla). Algunos de sus ocho hermanos también ocuparon importantes puestos, como Francisco de Paula, que fue ministro de audiencia; Fernando, quien llegó a ser canon - esto es, canónigo- en la Catedral de Salamanca; Bernardo, que hizo carrera militar; o Inés Vicenta, mujer del futuro intendente Manuel Jacinto Bringas y Galdames. ${ }^{3}$

Por su parte, además de Caballero de la Orden de Calatrava, Andrés Santos Samaniego fue académico supernumerario de la Academia de Buenas Letras de Valladolid y, desde el 27 de septiembre de 1746, también académico correspondiente de la Real Academia de Buenas Letras de Barcelona. Asimismo, ocupó el cargo de canónigo doctoral y prebendado en la catedral de Coria, desde donde colaboró en la Comisión de Archivos formada por orden de Fernando VI en 1749. Dirigida y centralizada por Andrés Marcos Burriel desde Toledo, dicha Comisión constituyó una gran empresa cultural, que, sin embargo, nació lastrada por su fuerte carácter político, pues su fin último no era sino proporcionar a la Corona la documentación necesaria, fundamentalmente eclesiástica, para defender sus intereses económicos ante la Santa Sede. ${ }^{4}$ En este marco, Santos Samaniego formó parte del amplio equipo de eruditos encargados de recopilar y estudiar los documentos conservados en los diferentes archivos del Reino, tal y como indica Luis José Velázquez de Velasco, autor sobre el que volveremos infra (el subrayado es nuestro):

Executóse lo mismo en otros Archivos del Reyno. A Madrid fue destinado D. Carlos de Simón Pontero; á Coria D. Andrés Santos; á Siguenza D. Antonio Carrillo; á Oviedo D. Atanasio de Torres; á Gerona el P. Antonio Codorniu; á Barcelona D. Andrés de Simón Pontero; á Zaragoza D. Josef de Luyando; á Valencia D. Miguel Eugenio Muñoz; á Cuenca, Murcia, Badajoz, y Plasencia D. Asensio de Morales; y á Cordova D. Marcos Domínguez y D. Josef Vázquez.

Burkholder s.d. [http://www.dbe.rah.es/biografias/35574/bernardo-santos-calderon-de-la-barca; consultado el 13/03/2020].

4 Una síntesis de la formación y motivación de esta Comisión en Hernando Sobrino 2017, 39-40, con la bibliografía previa. 
Todos los trabajos de estos pasaban al P. Burriel, á cuyo cargo estaba la combinación de todos ellos. ${ }^{5}$

A tales efectos, el nombramiento oficial de Santos Samaniego se produjo por orden real, que fue comunicada por José de Carvajal y Lancaster, Ministro Secretario de Estado, en una carta fechada el de 29 de abril de 1751. En ella podemos leer:

Atendiendo Su Majestad á las utilidades que resultarian á esta Monarquía si se diese al público una Historia Eclesiástica general de España, en cuya grande obra tan digna de sus Reales pensamientos, se interesa no ménos la gloria, lustre, honra y bien de la Religion y de la Iglesia universal, que el de la Iglesia de España en particular, del Estado y de la Nacion; y conociendo que este utilísimo proyecto no puede ejecutarse sin que se tengan presentes los preciosos monumentos y vastísimos materiales que hay sepultados (y aún olvidados y desconocidos y tal vez despreciados) en los archivos del Reino; y que para que una obra tan séria y de tanto interés pueda publicarse con la perfeccion, crítica, puntualidad y exactitud que se merece, es preciso recoger ante todas cosas cuanto haya conducente al asunto en todos los archivos del Reino (...) Y siendo uno de los que pueden contener materiales conducentes al logro del gran pensamiento de S. M. el de esa Santa Iglesia [i.e.: Coria], ha nombrado a Don Andrés Santos Calderon de la Barca, uno de los individuos de Vuestra Ilustrísima, para que lo reconozca, en atencion á su literatura y demás circunstancias. ${ }^{6}$

Fruto del cumplimiento de esta real orden serán las Memorias para la Historia de la Santa Yglesia de Coria (y) Chronología de sus Obispos, obra que Santos Samaniego remitió, acompañada de una carta fechada el 2 de marzo de 1752, a José de Carvajal y Lancaster que, además de Ministro Secretario de Estado -como ya se indicó-, era miembro de la Junta del Real Patronato que patrocinó la formación de la propia Comisión de Archivos. ${ }^{7}$

Poco más sabemos de Santos Samaniego salvo que, con posterioridad, abandonó Coria para regresar a su Salamanca natal. En el Compendio histórico que de esta ciudad escribió Bernardo Dorado, en el último cuarto del siglo XVIII, será registrado entre sus hombres "ilustres en letras, de este mismo siglo" en los siguientes términos:

El Doctor Don Andrès Santos, y Samaniego, Cavallero del Militar de Calatrava, Canonigo Doctoral de la S. Iglesia de Coria, y Penitenciario de esta, de el Gremio, y Claustro de esta Universidad, y su Catedratico de Canones, y Vice-Cancelario, Provisor, y Vicario General de este Obispado, Sede Vacante. ${ }^{8}$

En Salamanca había fallecido el 17 de octubre de 1765.

Por lo que respecta a la fortuna de sus Memorias, cierto es que no pasaron desapercibidas, pues Tomás Muñoz y Romero se hará eco de las mismas en su célebre

\footnotetext{
Velázquez de Velasco 1765, 9-10. En todas las citas se respeta la ortografía y puntuación del original.

Santos Samaniego s. XVIII, ff. 54-55; de esta obra, correspondiente al Ms. 13.078 de la Biblioteca Nacional de España, depende, como se verá, este trabajo.

Hernando Sobrino 2009, 98, y 2017, 400.

Dorado 1776, 562.
} 
Diccionario, en el que da cuenta, además, de la existencia de dos copias distintas: "Ms. en fól., en la Biblioteca Nacional, DD 97 y en la Academia de la Historia C 8, fol. 1 al 62"; 9 esto es, los actuales manuscritos 13.078 de la Biblioteca Nacional ${ }^{10}$ y 9-5428 de la Real Academia de la Historia. ${ }^{11}$ No obstante, y pese al notable interés de los datos compilados en la obra, ${ }^{12}$ su conocimiento y aprovechamiento fue bastante tardío en lo que al ámbito de la epigrafía se refiere.

\section{La traditio sobre la epigrafía cauriense}

Aunque el territorio extremeño despertó el interés de los estudiosos de epigrafía desde los inicios de la tradición epigráfica humanística hispana, en el siglo XV, manteniéndose muy vivo en las centurias posteriores, tal interés se centró de modo fundamental en Mérida, Cáparra, el Puente de Alcántara $\mathrm{y}$, en menor medida, Cáceres. ${ }^{13}$ Por el contrario, otros núcleos romanos de dicho territorio que, a diferencia de los citados, carecían de vestigios monumentales o de relieve, o no se encontraban en el recorrido de la Vía de la Plata - cuyo itinerario transitaron no pocos eruditos, transmitiendo tanto los epígrafes de sus principales ciudades como los numerosos miliarios que jalonaban la antigua calzada- ${ }^{14}$ permanecieron prácticamente inexplorados, desde el punto de vista epigráfico, hasta el siglo XVIII.

Y así parece que ocurrió con la epigrafía de la antigua Caurium, ${ }^{15}$ tal y como se desprende del hecho de que las fuentes de las que se sirvió Emil Hübner para componer su colección epigráfica en el CIL II se datan, si exceptuamos a Gaspar de Castro, Florián de Ocampo y Fray Francisco de Coria, ${ }^{16}$ prácticamente todas a

Muñoz y Romero 1858, 108, nº 3 .

10 El manuscrito fue ya identificado en Gimeno Pascual 1993, 299, n 67, y catalogado en Hernando Sobrino 2009 , 400-401.

11 Esta signatura la hemos tomado del repertorio bibliográfico relativo al patrimonio de Coria elaborado por J. A. Espada Belmonte en 2008, consultado en red [https://issuu.com/pfecoria/docs/biblio, consultado el día 6/09/2020; véase la página 53 del documento]. Esta signatura se inserta, según la versión digital de J. M. Abascal del Catálogo general de manuscritos de la Real Academia de la Historia (1910 - 1912), en la colección de Privilegios y escrituras que se hallan en el archivo y tumbo de las siguientes catedrales, formada por Ascensio de Morales y compuesta por 23 volúmenes de manuscritos datados en el siglo XVIII [https://www. yumpu.com/es/document/read/14084454/catalogo-general-de-manuscritos-real-academia-de-la-historia; véase la entrada Catedrales de España; consultado el día 6/06/2020].

12 Véase, a modo de ejemplo, el trabajo elaborado por Fita en 1882, relativo a las actas, inéditas, de siete concilios españoles de época medieval compiladas por Santos Samaniego.

13 Adviértase, por ejemplo, cómo las inscripciones romanas de Mérida, Cáparra y Alcántara constituyen la práctica totalidad del material epigráfico extremeño recogido en el Codex Valentinus, nombre con el que se conoce a un manuscrito conservado en la Biblioteca Nacional (Ms. 3.610), datado entre los siglos XVI y XVII y que contiene una de las más importantes y antiguas colecciones de inscripciones hispanas (véase Gimeno Pascual 1997, 138-143, 147-148, 154-157 o 161-162 entre otras; igualmente, Hernando Sobrino 2009, 187). Para los primeros trabajos epigráficos en el territorio extremeño véase Cerrillo Martín de Cáceres 2007, 13-17; sobre la tradición epigráfica de la villa de Cáceres, véase Cerrillo Martín de Cáceres 2001-2002.

14 Una completa transcripción del relato de Velázquez sobre su recorrido por la Vía de la Plata, en Roldán 1971, 185-191. También acerca de este itinerario, Ponz 1778, 12-44 y 86-104; Viu 1852, 74-120 (para el tramo extremeño del camino) o Guerra 1865, 6-28.

15 Nótese, en este sentido, la ausencia de inscripciones procedentes de Coria entre los más de mil epígrafes recogidos en el ya citado Codex Valentinus (Gimeno Pascual 1997; Hernando Sobrino 2009, 187).

16 Con Gaspar de Castro, beneficiado de Ledesma y canónigo de Salamanca de mediados del siglo XVI (cf. CIL II, p. IX, 12), se relacionan CIL II 787 y 789. Del zamorano Florián de Ocampo (1499? - 1555?), cronista de Carlos 
partir de mediados del siglo XVIII. Dicho de otro modo, su conocimiento obedeció básicamente al clima favorable que, para el desarrollo de la Epigrafía, comportó la Ilustración, respaldada por la política de los Borbones, por más que esta -como ya hemos indicado- no siempre estuviese movida por razones estrictamente culturales. ${ }^{17}$

En CIL II Hübner registrará finalmente un total de 41 inscripciones adscritas a Coria, ${ }^{18}$ una cifra que no se aleja mucho de las 53 recogidas para Cáparra ${ }^{19} \mathrm{o}$ de las 66 correspondientes a la antigua Norba Caesarina.$^{20}$ Buena parte de estas inscripciones se encontraban reutilizadas en las murallas de la ciudad, esto es, en el mismo lugar en que Santos Samaniego va a identificar las inscripciones que menciona en su obra (Fig. 1). Sin embargo, Hübner no conoció la obra del salmantino y, para la epigrafía cauriense, como veremos a continuación, se nutrió esencialmente de la información aportada por Luis José Velázquez de Velasco (para las inscripciones que nos interesan aquí, CIL II 770, 771, 788 y 790) y Felipe León Guerra (CIL II 770, 771, 783 y 790), así como también, aunque de forma más tangencial, por Antonio Ponz (CIL II 771, 788 y 790), José de Viu (CIL II 770, 771, 788 y 790) y Claudio Constanzo (CIL II 770).

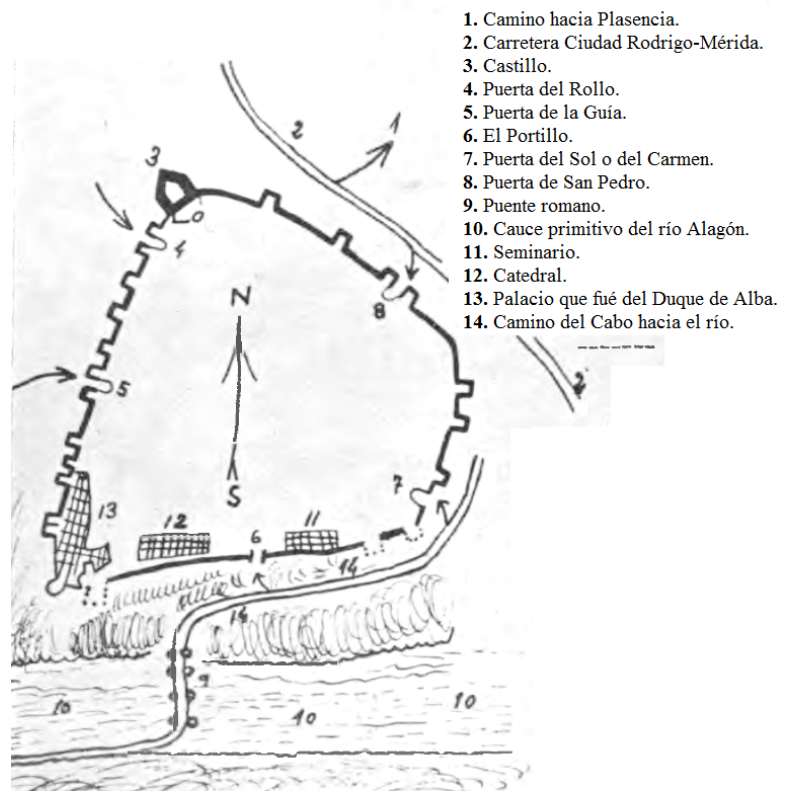

Fig. 1. Plano de Coria y sus murallas (Velo y Nieto 1968, 188).

V, dependen los registros de CIL II 799, 800 y 801 (cf. CIL II, pp. XII-XIII, 26; Gimeno Pascual 1997, 23-148). Sobre las inscripciones, apenas un par, que dependen de la Descripcion Historica y general de la Provincia de Extremadura de Fray Francisco de Coria (Coria, ca. 1550 - Sevilla, ca. 1609), fechada en 1608, volveremos infra (§ 4). A estas inscripciones habría que añadir CIL II 794 que, si bien tomada de Cornide, parece depender de Jerónimo Román de la Higuera (1538-1611).

17 Un sintético pero bien documentado panorama de la investigación epigráfica hispana en el siglo XVIII en Hernando Sobrino 2017, 13-63. Y esta misma realidad, aplicada al caso concreto de la región extremeña, en Cerrillo Martín de Cáceres 2007, 18-20.

18 CIL II 763-803. Inexplicablemente, Martínez 1901, 348, dice que el sabio alemán solo recogió 29 inscripciones caurienses.

19 CIL II 804-856.

20 CIL II 692-758. 
Los problemas de transmisión y fiabilidad que presentan algunas de las fuentes empleadas por Hübner son expuestas, por ejemplo, por Martínez (quien, sin embargo, olvida por completo el papel de Velázquez al respecto):

Nada menos que 29 inscripciones de Coria inserta AEmilio Hübner en el Corpus inscriptionorum Hispaniae Latinae, todas ellas tomadas del manuscrito de Claudio Constanzo sobre epígrafes extremeños y de las Notas que escribió Don Felipe León Guerra acerca de la Colección de José Viú. Aunque el segundo de los coleccionistas merezca alguna fé en lo concerniente á exactitud, se tropieza en ambos con el inconveniente de que no todas las inscripciones están bien copiadas, y sería muy de desear que los amantes de la historia las recuperasen para poder afirmar la lectura de ellas á la luz de buenos calcos. ${ }^{21}$

Los primeros datos relacionados con la epigrafía de Coria, de entre las principales y más fructíferas fuentes consultadas por Hübner para la redacción del CIL II, vienen de la mano de dos "viajes literarios" 22 bien conocidos, aunque de fortuna bien diferente: el de Luis José Velázquez de Velasco, cuya documentación ha permanecido prácticamente en el olvido hasta fechas recientes; y el de Antonio Ponz, que se publicó casi de manera inmediata y obtuvo un notabilísimo éxito.

Entre las numerosas inscripciones que recopiló al hilo de su célebre viaje, ${ }^{23}$ Luis José Velázquez de Velasco (Málaga, 1722 - 1772), erudito ilustrado más conocido por su título de marqués de Valdeflores, anotó siete localizadas en Coria, siendo sus datos seguidos por Hübner para confeccionar las entradas correspondientes a $C I L$ II 770, 771, 773, 781, 784, 788 y 790, en las que el malagueño figura siempre como fuente más antigua. ${ }^{24}$ No obstante, y como el propio Velázquez indica, las registró durante su estancia en Coria el 15 de mayo de $1753,{ }^{25}$ lo que significa que

21 Martínez 1901, 348. Como veremos, para la parte relativa a Coria del CIL II, Hübner no se basó, en realidad, en las notas de Guerra (1865) sobre la obra de Viu, sino eminentemente en el manuscrito original del propio Guerra (1840), titulado Lápidas romanas de la ciudad de Coria, copiadas y remitidas a la Academia de la Historia... (Ms. RAH-CC-9-3931-4/2).

22 Para una panorámica sucinta sobre la importancia de este género en el siglo XVIII y para el anticuariado, véase el trabajo de Abascal Palazón 2012.

23 El viaje - que contó con el apoyo de la Corona, pero fue auspiciado fundamentalmente por la Real Academia de la Historia, de la que el marqués fue nombrado académico supernumerario en 1751- vendría a completar, recopilando documentos de la historia civil de España, el trabajo desarrollado en paralelo por el ya citado Burriel para la Comisión de Archivos. Para este viaje véase la reciente edición a cargo de Maier Allende (Velázquez de Velasco 2015). La importancia del marqués de Valdeflores para la epigrafía hispana, ya señalada por Hübner en CIL II, p. XXII, 70, ha sido destacada con posterioridad en Canto 1994 y Hernando Sobrino 2017, 46-51, entre otros.

24 Velázquez de Velasco 1753a (f. 15v para las inscripciones de la muralla de la ciudad). Transcrito luego por Cornide 1798-1801a y 1798-1801b, donde vuelve a registrar las inscripciones CIL II 770, 771, 773, 781 y 790.

25 Velázquez de Velasco 1753b, f. 2v (transcripción y comentario de J. M. Abascal Palazón en http://www. cervantesvirtual.com/obra-visor/informe-a-la-real-academia-de-la-historia-sobre-su-viaje-a-extremaduraentre-1752-y-1753-2-de-octubre-de-1753-documento-cag9798000542-del-archivo-de-la-real-academia-dela-historia-en-madrid--0/html/001c701c-82b2-11df-acc7-002185ce6064_2.html; consultado el 06/06/2020). Sobre las fechas del viaje de Velázquez, Abascal Palazón - Cebrián Fernández 2005, 467, indican que: "las fechas exactas de los viajes fueron siempre motivo de duda entre sus contemporáneos y entre quienes emplearon su documentación en la centuria siguiente. Baste decir que en el archivo de la propia Academia hay algunas notas cruzadas a lo largo del siglo XIX entre diferentes investigadores tratando de esclarecer ese asunto; la conclusión a que llega una de las más fundamentadas (Ms. RAH-9-7364-69zzñ) es que el viaje de Extremadura comenzó el 10 de septiembre de 1753, cuando el propio Valdeflores indica que esa es la fecha en que cruzó la divisoria entre Extremadura y Andalucía al final del primero de los recorridos". 
estuvo en dicha localidad en una fecha posterior a la estancia en la misma de Santos Samaniego. Este dato convierte al salmantino, como destacaremos más adelante, en el primer autor que dio cuenta de la existencia de las inscripciones romanas que recoge en su obra.

Años más tarde, siendo ya rey Carlos III, visitaría Coria Antonio Ponz (Bejís, 1725 - Madrid, 1792) quien, en este caso por propia iniciativa, inició en 1771 un viaje con el fin de realizar un catálogo completo de las obras de arte y antigüedades de España. En el tomo VIII de su Viaje de España, dedicado a Extremadura, registró que en las murallas de Coria:

hay puestas inscripciones antiguas; una vi sobre la puerta que hoy llaman de la Guía, con dos cabezas casi consumidas sobre el letrero, otra en el castillo y otra en el palacio del señor. Las más están casi ilegibles. Sólo tuve tiempo y habilidad para entresacar de algunas lo siguiente. ${ }^{26}$

El autor mencionará a continuación un total de seis inscripciones, correspondientes a $C I L$ II 771, 773, 781, 784, 788 y 790. Como fácilmente puede deducirse, todas habían sido ya registradas previamente por Velázquez, si bien ello no resta valor a su testimonio. ${ }^{27}$

Posteriormente será Claudio Constanzo (Alba de Tormes, 1773 - Cáceres, 1843), escribano real y, como los eruditos previos, también correspondiente de la Real Academia de la Historia, quien ofrezca noticias valiosas al respecto de la epigrafía cauriense. ${ }^{28}$ Conoció Coria siendo administrador de las propiedades del Marqués de Santa Marta, cargo en virtud del cual recorrió gran parte de la provincia de Cáceres, estudiando sus antigüedades y monumentos. ${ }^{29}$ Así, en su Colección de lápidas y otros monumentos antiguos descubiertos y averiguados en esta villa de Cáceres, sus inmediaciones y en otras poblaciones de la provincia de Extremadura, hasta hoy primero de junio de este año de 1800, publicada en su forma definitiva en $1836,{ }^{30}$ registrará un total de doce inscripciones de la localidad ( $n^{\circ}$ 96-107), ${ }^{31}$ correspondientes a $C I L$ II 764, 767, 770, 772, 773, 774, 776, 777, 778, 781, 782 y 784.

Entre 1833 y 1838, será Felipe León Guerra y Cumbreño (Sierra de Fuentes, 1807 - Gata, 1890), médico, profesor en el seminario de Coria y muy aficionado a las antigüedades, quien se interese por la epigrafía romana de la localidad. ${ }^{32} \mathrm{Su}$ comunicación Lápidas romanas de la ciudad de Coria..., con fecha del 18 de febrero

26 Ponz 1778, 53-54.

27 Véanse las palabras de Hübner en CIL II, p. XXIII, 74, así como la valoración de su labor en el campo de la epigrafía que realiza H. Gimeno Pascual en la sección de anticuarios y epigrafistas de la página web del centro CIL II [http://www3.uah.es/imagines cilii/Anticuarios/Textos/ponz.htm; consultada el día 6/09/2020].

28 Para su figura y su labor como epigrafista, véase el fundamental el trabajo Cerrillo Martín de Cáceres 2007.

29 Cerrillo Martín de Cáceres 2007, 75. Para este autor, las informaciones de Constanzo sobre las diferentes localizaciones de las inscripciones caurienses en la muralla o en el castillo, entre otros datos, permiten pensar que si no fue él mismo quien las copió, sí debió basarse en un informante directo.

30 Cerrillo Martín de Cáceres 2007, 10.

31 Numeración según la edición de Cerrillo Martín de Cáceres 2007, 169-175. Más allá del estudio personal de las piezas objeto de su interés, como apunta Jiménez Navarro $(1949,341)$ : "El autor no pretendió hacer un tratado completo y sistemático de las antigüedades extremeñas; más bien se limitó a recoger cuantas inscripciones pudo ver o estudiar en autores anteriores, aunque utilizando el material con muy buen criterio".

32 Para la vida y obra de Guerra véase Fernández Serrano 1958. 
de $1840,{ }^{33}$ constituye la principal fuente de la que se serviría Hübner en lo relativo a la epigrafía romana cauriense, como el propio sabio alemán reconoce. ${ }^{34}$ Guerra registra las inscripciones correspondientes a $C I L$ II 763, 765, 766, 768, 769, 771, $772,773,775,778,779,780,781,782,783,784,785,786$ y 792 . Apunta igualmente Guerra que ya Constanzo y Ceán Bermúdez ${ }^{35}$ habían tratado sobre ellas y reconoce, asimismo, que no llegó a ver personalmente todos los epígrafes de los que habla. ${ }^{36}$ Años más tarde, y en sus Notas á las Antigüedades de Extremadura de D. José Viú, volverá a hablar de la existencia de estas mismas inscripciones:

En Coria, donde estube últimamente desde Octubre de 1833 hasta fines del año de 1838 , se hallan dos puertas evidentemente romanas en su muralla, que no lo es en lo demás, á no ser los cimientos, si acaso; pero está tan llena de lápidas de aquel tiempo que á nada que se la desbarate no deja de salir alguna de ellas. ${ }^{37}$

Efectivamente, también José de Viu (Torla, fines s. XVIII - Valencia de Alcántara, 1857) había transitado por estas calles caurienses. De formación jurídica, el autor inició su interés por las antigüedades extremeñas tras su llegada como juez de Primera Instancia a Cáceres en 1820 y, sobre todo, por su matrimonio con la alcantarense Petra Gundín Arias. Fruto de sus trabajos de campo, y bajo los auspicios de la Comisión de monumentos históricos y artísticos de Cáceres, publicó su obra Extremadura: Colección de sus inscripciones y monumentos... de $1852,{ }^{38}$ en la que, al tratar de la colección epigráfica de Coria, dejó indicado que "en la cara esterior de las murallas hay un sinnúmero de piedras con inscripciones que ya no pueden leerse", ${ }^{39}$ para trasmitir luego las someras descripciones de ocho epígrafes: CIL II $770,771,773,781,784,788,790$ y 802 , este último en realidad procedente de Villanueva de la Sierra (como ya apreciasen Ceán Bermúdez o Guerra). ${ }^{40}$

Estos son, en suma, los principales autores y obras de que se sirvió Hübner para la confección del capítulo relativo a Coria en CIL II. Obviamente, tras la edición del Corpus se seguirían produciendo los hallazgos y ediciones de nuevos epígrafes de la localidad. ${ }^{41}$ De este modo, en 1977, Hurtado San Antonio recogía ya en su Corpus Provincial de Inscripciones Latinas de Cáceres (CPILC) un total de 51 epígrafes

33 Ms. RAH-CC-9-3931-4/2 (cf. Abascal Palazón - Cebrián Fernández 2005, 276).

34 Hübner en CIL II, p. 97, donde el autor es descrito como homo Latinitatis apprime gnarus, lapidum descriptor accuratissimus.

35 Ceán Bermúdez 1832, 409-410. Aunque el autor no llegó a visitar Coria (por lo que, obviamente, no vio personalmente las inscripciones que transmite), en el breve apartado que dedica a Coria en su Sumario de las antigüedades romanas que hay en España recoge los textos de CIL II 771, 773, 790 y 802.

36 Como veremos, Hübner considera que quizá consultó y tomó inscripciones de la obra de Francisco de Coria, datada en 1608 .

37 Guerra 1865,35 .

38 La epigrafía constituirá la principal fuente de información para esta obra, si bien, dados sus errores, años más tarde será contestada por Felipe León Guerra (Guerra 1865). No obstante, y pese a estos errores, cabe atribuir a la obra de José de Viu el mérito de ofrecer por primera vez una visión de conjunto del patrimonio arqueológico y de la Historia Antigua de la región extremeña (cf. Cerrillo Martín de Cáceres s.d.).

39 Viu $1852,175$.

40 Ceán Bermúdez 1832, 409; Guerra 1865, 177.

${ }^{41}$ A modo de selección, y sin pretender ser exhaustivos a este respecto: Fita 1905; Mélida 1908; Thouvenot 1940; Morán 1945; Ramón y Fernández Oxea 1955; Corchón García 1955; Díaz Martos 1957 y 1961; Rodríguez Hernández 1966; o Martín Valls 1970. 
procedentes de esta localidad. ${ }^{42}$ En 1998, en la primera obra monográfica sobre la epigrafía latina de Coria (ILC), Sánchez Albalá y Vinagre Nevado prácticamente doblan esta cifra y recogen ya 96 inscripciones ${ }^{43}$ presentando hasta 21 epígrafes inéditos ( $\mathrm{n}^{\circ}$ 91-111). Y lo que nos resulta más importante, citan ya a nuestro erudito ilustrado como fuente para cuatro inscripciones (ILC 49, 63, 65 y 67). Por su parte, más recientemente, en el cuarto volumen de su Corpus de Inscripciones Latinas de la Provincia de Cáceres (volumen dedicado precisamente a la antigua Caurium y su territorium, CILCC IV), Esteban Ortega corrige algunas de las identificaciones planteadas por Sánchez Albalá y Vinagre $\mathrm{Nevado}^{44}$ y registra cuatro epígrafes de la localidad hasta la fecha inéditos, ${ }^{45}$ reuniendo, así, un total de 87 inscripciones latinas en Coria. ${ }^{46}$

\section{Las inscripciones recogidas por Santos Samaniego a la luz del Ms. 13.078 de la BNE}

Como ya hemos avanzado, el Ms. 13.078 de la Biblioteca Nacional de España recoge la obra Memorias para la Historia de la Santa Yglesia de Coria (y) Chronología de sus Obispos. Procedente del fondo documental vinculado con Burriel, para quien como vimos- trabajó el autor en el marco de la Comisión de Archivos, el volumen ${ }^{47}$ viene precedido por un índice y la ya citada carta dirigida a Carvajal y Lancaster que acompaña el envío de la Memoria. Es en este contexto introductorio, previo al grueso de la obra y tras unas Observaciones y vrebe extracto de los Misales antiguos estudiados por el autor en la catedral de la localidad (ff. 46-48), en el que se inserta un breve excurso sobre las inscripciones observadas por el autor en las murallas de Coria, titulado Characteres que se registran en las piedras puestas en las murallas de la ciudad de Coria (ff. 48v-49r).

Se trata de dos folios, escritos a renglón seguido de los apartados anterior y posterior y sin relación con el contenido del resto de la obra, en los que el autor registra, sin numerarlas, seis inscripciones de las que ofrece localización, medidas y, también, dibujos. Como bien ha señalado, entre otros, Gimeno Pascual, ${ }^{48}$ la búsqueda de datos inéditos en los manuscritos sobre epigrafía no suele resultar tan fructífera como a priori pudiera esperarse, siendo infrecuente incluso en fuentes de carácter local, como la que aquí nos ocupa. Y lo cierto es que ninguna de las seis inscripciones

42 CPILC 204-247; CPILC 739-742; CPILC 771-772 y CPILC 809.

$43 \quad I L C 1-96$.

44 Así por ejemplo, ILC 27 y 28 (=CILCc IV 1194) son editadas como una única inscripción, de la misma forma que ILC 32 y 33 (=CILCC IV 1197); ILC 50 y 51 (=CILCC IV 1213); ILC 74 y 85 (=CILCc IV 1231); o que ILC 38 y 80 (=CILCC IV 1236). También Esteban Ortega corregirá algunas identificaciones erróneas y duplicidades introducidas por Hurtado San Antonio: así CPILC 243 y 741 (=CILCC IV 1194); CPILC 639 y 641 (=CILCc IV 1310); y CPILC 226 y 645 (=CILCC IV 1333). Por su parte, ya en su reseña de ILC Mantas $(2002,281-282)$ llamaría la atención acerca del origen extra cauriense de dos inscripciones recogidas erróneamente por Sánchez Albalá y Vinagre Nevado como provenientes de Coria (ILC 25 y 60); consideraría como modernas -y no como romanas- las inscripciones $I L C 69$ y 72 y advertiría la duplicidad de las inscripciones $I L C 27=I L C 28 ; I L C 32$ $=I L C 33 ; I L C 50=I L C 51$ e ILC $63=I L C 64$ (véase más abajo sobre este último caso).

45 CILCC IV 1248; CILCC IV 1250-1252.

$46 \quad$ CILCC IV 1168-1254.

47 Las características físicas del manuscrito pueden encontrarse en Hernando Sobrino 2009, 400.

48 Gimeno Pascual 1997, 222. 
transmitidas por nuestro anticuarista salmantino es inédita (Tabla 1). Sin embargo, no lo es menos que, aunque de cinco de ellas se tiene noticia desde los siglos XVIIIXIX, la sexta, como destacaremos infra, no fue conocida por la comunidad científica hasta a mediados del siglo XX, siendo publicada como inédita.

$\begin{array}{cccccccc}\text { № } & \underline{\text { CIL }} \underline{\text { II }} & \underline{\text { HAE }} & \underline{\text { ILC }} & \underline{\text { CPILC }} & \underline{\text { CILC }} \underline{\text { IV }} & \underline{\text { HEp }} & \underline{\text { HEpOL }} \\ \text { I } & 790 & - & 65 & 222 & 1226 & - & 18992 \\ \text { II } & 770 & - & 49 & 225 & 1212 & - & 21748 \\ \text { III } & 783 & - & 44 & 247 & 1207 & - & 18985 \\ \text { IV } & 788 & 777 & 63 & 219 & 1224 & 1998,78 \mathrm{a}-\mathrm{b} & 18990 / 25882 \\ \text { V } & 771 & - & 18 & 223 & 1186 & - & 21749 \\ \text { VI } & - & 2213 & 67 & 809 & 1228 & 1998,79 & 23423\end{array}$

Tabla 1. Correspondencias de las inscripciones recogidas por Santos Samaniego.

La brevedad de los apuntes epigráficos de Santos Samaniego, así como su clara desconexión con el resto de la obra, deben relacionarse con la misión que le fue encomendada al autor en el marco de la Comisión de Archivos, que no fue sino la recopilación y estudio de la documentación de la catedral de Coria. Y, justo por ello, tales apuntes constituyen un buen ejemplo del interés mostrado por la mayor parte de los eruditos y anticuarios del siglo XVIII en la colección y estudio de epígrafes, monedas y medallas, aspecto este ya destacado por otros autores. ${ }^{49}$ Llegados a este punto, resulta cuando menos sorprendente que Hübner no conociese la obra de Santos Samaniego. Y es que, si bien el manuscrito 9-5428 de la Real Academia de la Historia se halla integrado en la colección de Privilegios y escrituras que se hallan en el archivo y tumbo de las siguientes catedrales (colección cuyo mero título, a priori, no permite sospechar que contenga información de carácter epigráfico), extraña que el sabio alemán no cotejase el manuscrito 13.078 de la Biblioteca Nacional pues sabemos que, para la elaboración del CIL II, vació otras obras de contenido y título similares.

Cabe reconocerle a Santos Samaniego, por tanto, el mérito de haber recogido estos distintos epígrafes caurienses. E igualmente cabe destacar que sus noticias se daten, al menos, cerca de un año antes que las proporcionadas por la otra fuente principal sobre la epigrafía de Coria, esta sí interesada específicamente en la colección epigráfica de la localidad: el Marqués de Valdeflores quien, como ya adelantamos, visitó Coria el 15 de mayo de 1753. Y es que la data del 2 de septiembre de 1752 que aparece en la carta enviada por Santos Samaniego a Carvajal y Lancaster constituye la fecha ante quem para la inspección ocular y anotación de las inscripciones caurienses por parte del erudito salmantino, detalle que, como se adelantó, convierte a nuestro autor en el primero en dar cuenta de la existencia de estos epígrafes.

Por lo que respecta a las distintas inscripciones anotadas por Santos Samaniego, debemos comenzar precisando que no pretendemos sino destacar los datos originales y novedosos que el autor aporta para su conocimiento, cotejándolos con las noticias transmitidas por los autores que fueron más o menos contemporáneos, y siempre en el contexto general de la historia de la investigación acerca de la epigrafía

49 Véase Hernando Sobrino 2017, 39-40. 
cauriense. Por ello, en unos epígrafes nos centraremos en los datos relativos a sus aspectos formales (medidas, formato, decoración), datos que solo Santos Samaniego proporciona; mientras que, en otros, incidiremos en la información relativa al contenido textual de los epígrafes y en el valor del testimonio del autor salmantino para clarificar lecturas en ocasiones problemáticas y discutidas.

Con el fin de poner de relieve la singularidad de la información de carácter textual ofrecida por Santos Samaniego sobre estas inscripciones, las variantes de lectura observadas no serán recogidas a la manera usual de los repertorios epigráficos, sino por medio de tablas que, en nuestra opinión, permiten precisar de manera más clara las originalidades de lectura o de distribución en líneas aportadas por Santos Samaniego, facilitando su cotejo con las lecturas proporcionadas por los diferentes autores que las han estudiado. Las restituciones textuales de tales inscripciones, al margen de las lecturas aportadas por Santos Samaniego o por otros autores de los siglos XVIII y XIX, así como la información relativa a sus características formales o a sus medidas se basarán principalmente en los corpora más actuales, esto es, en $I L C$ y $C I L C C$ IV.

\subsection{Inscripción I (Figs. 2-3)}

"Primeramente se registra una piedra de una bara de alto y más de tertia de ancho, que tiene esta figura y dice:

venic / A. Pisir / I. AN. IX / P. C.

Laqual esta a la parte del norte, junto a la esquina de la que hace frente al Oriente". ${ }^{50}$

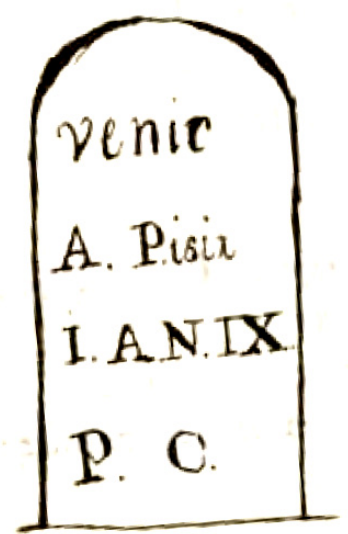

Fig. 2. Inscripción I de Santos Samaniego (Ms. BNE 13078, f. 49).

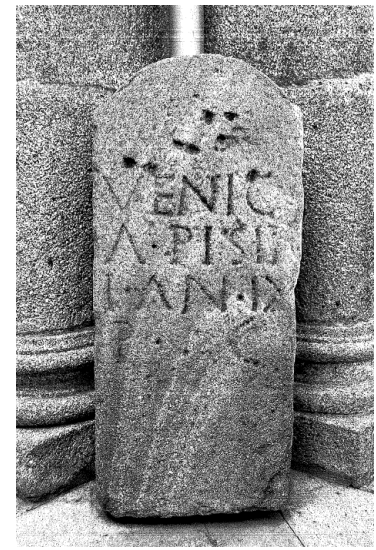

Fig. 3. Estela de Venica (Esteban Ortega 2017, 256).

50 Velázquez de Velasco 1753a, f. 15v, no 1 (transcrito luego por Cornide 1798-1801a y 1798-1801b, f. s/n); Ponz 1778, 54, nº 1; Ceán Bermúdez 1832, 409 (tomado por Guerra 1840, f. s/n, sin dibujo); Viu 1852, 175-176 (transmitido luego por Guerra 1865, 36, n 7); CIL II 790; Martínez 1901, 355, n 16; CPILC 222; ILC 65 (con fotografía); CILCc IV 1226 (con fotografía, p. 256); HEpOL 18992. 


\begin{tabular}{|c|c|c|c|c|c|}
\hline$\underline{\text { Santos }}$ & Velázquez & Ponz & Guerra (1865) & $\underline{\text { Viu }}$ & Hübner \\
\hline$\overline{\text { venic }}$ & VENIC & 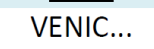 & VENIC & VENIC $\cdots \cdots$ & $\overline{\text { VENIC }}$ \\
\hline A. Pisir & A PISITV & A. PISITN... & A - PISIT. & A $\cdot$ PISNT $\ldots \ldots$ & A. PISII+ \\
\hline I. AN. IX & I AN IX & AN. IX & & $|\cdot A N \cdot| X \cdots$ & $I \cdot A N \cdot I X$ \\
\hline P. C. & PC & F.C. & & $\cdots F \cdot C$ & $P \cdot C$ \\
\hline
\end{tabular}

Tabla 2. Variantes de lectura de la Inscripción I.

Restitución textual: Venic/a $\cdot$ Pisir ${ }^{\beta} i \cdot \operatorname{an}($ norum) $I X / p$ (ater) $\cdot c$ (uravit)

Tal y como puede apreciarse, la lectura ofrecida por Santos Samaniego es en todo correcta. Habida cuenta de que el autor aún la vio integrada en la muralla, de donde la inscripción se extrajo a mediados del siglo XX (véase infra), este dato certificaría, ya de entrada, el buen hacer del autor en la materia.

Uno de los aspectos más llamativos relativos a esta pieza, correspondiente a una estela, radica en el hecho de que, desde el siglo XVIII, algunos informadores le atribuyen una decoración consistente en dos presumibles retratos en su cabecera. Ceán Bermúdez dice que "la que está sobre la puerta llamada de la Guía, con dos cabezas disfiguradas sobre el letrero", mientras que Viu anota, igualmente, que "está sobre la puerta de la Guía con dos cabezas desfiguradas sobre el testero". Incluso, en fechas más recientes, Velo y Nieto, siguiendo a Viu, seguirá apuntando en esta misma dirección:

Siempre ha estado empotrada encima del arco una piedra con un epígrafe que no ha podido ser interpretado total y fielmente, por aparecer las letras medio borradas. El texto que se conoce es el siguiente [recoge aquí la lectura de Viu]. En dicha piedra, que es una lápida sepulcral, además de este geroglífico, existían dos cabezas talladas, sin apenas relieve por la acción del tiempo; y sólo ha podido colegirse que perteneció la misma a una niña de nueve años. ${ }^{51}$

Curiosamente, Santos Samaniego nada dice - ni en su descripción ni en el dibujo que acompaña el registro- sobre estas "cabezas" de cuya existencia dan cuenta Ceán Bermúdez y Viu. De hecho, esta decoración parece quedar descartada a luz de las descripciones y fotografías de los autores que la han estudiado más recientemente, una vez extraída del lienzo murario de la ciudad.

Creemos muy posible que el dato relativo a estos retratos partiese de una mala comprensión de la información aportada por Ponz al respecto de las inscripciones de la cerca de Coria. Para una mayor claridad en la exposición repetimos aquí, ampliada, la cita que de este autor ya anotamos supra (véase $\S 2$; el subrayado es nuestro):

En varios parajes de dichas murallas hay puestas inscripciones antiguas; una vi sobre la puerta que hoy llaman de la Guía, con dos cabezas casi consumidas sobre el letrero, otra en el castillo y otra en el palacio de señor. Las mas están casi ilegibles. Sólo tuve tiempo y habilidad para entresacar de alguna lo siguiente

$\mathrm{Y}$, a continuación, registra los textos de seis inscripciones, siendo su $\mathrm{n}^{\mathrm{o}} 1$ esta que nos ocupa y su $\mathrm{n}^{\mathrm{o}} 3$ la que registramos infra con el $\mathrm{n}^{\circ} \mathrm{V}$. Parece obvio que Ceán

$51 \quad$ Velo y Nieto $1968,192$. 
Bermúdez primero, y después Viu, relacionan de modo automático las tres primeras inscripciones de la serie ofrecida por Ponz con las tres localizaciones que este ofrece en la presentación. De esta relación se deduce, además de su asociación con la Puerta de la Guía (en el lado oriental de la cerca), la presencia del motivo decorativo en discordia. Pero lo cierto, vista la cita de Ponz, es que este no vincula expresamente las tres localizaciones que menciona con las tres primeras inscripciones que ofrece numeradas.

Frente a su relación con la "puerta de la Guía", señalada por Ceán Bermúdez y Viu, ${ }^{52}$ Santos Samaniego la localiza "a la parte del norte", precisamente donde se encuentra la "puerta de San Ginés, hoy de la Corredera", señalada por otras fuentes, ${ }^{53}$ y que en la actualidad, si nuestros datos son correctos,${ }^{54}$ efectivamente corresponde a la denominada puerta de San Pedro (Fig. 1). En una fecha por concretar, la inscripción fue extraída y depositada en el patio del Ayuntamiento de Coria, donde ya la vieron y analizaron Sánchez Albalá y Vinagre Nevado y, más recientemente, Esteban Ortega, para ser finalmente trasladada al Museo de la Cárcel Real de la localidad, donde aún se encuentra hoy. ${ }^{55}$

Así pues, no podemos negar la existencia de un epígrafe localizado en la Puerta de la Guía y con las características decorativas apuntadas por Ponz. No obstante, creemos que no guarda relación con este que aquí nos ocupa.

De todos los autores anteriores al siglo XX que trataron sobre esta pieza, Santos Samaniego es el único que nos ofrece sus medidas: "una bara de alto y más de tertia de ancho", es decir, unos $83 \times 27 \mathrm{~cm}$. Dado que este autor la vio estando aún en las murallas y en una posición elevada, cabe reconocerle el mérito de aproximarse a las dimensiones de $91 \times 42 \times 15^{56}$ o $90 \times 42 \times 22^{57}$ anotadas por quienes ya tuvieron la oportunidad de realizar su autopsia una vez extraída de la muralla.

\subsection{Inscripción II (Fig. 4)}

"Otra halli mismo, que se reconoce estar quebrada, y tiene esta figura y letras, de media bara:

Mancinus LA./cari F. AN. XXX / Aur ex :: te :::: ia :::::: / ncina ::: t ÂNC :::::::: /i. F. H. S. C." ${ }^{58}$

Ceán Bermúdez 1832, 409, y Viu 1852, 175-176.

En CIL II 790 -siguiendo a Guerra- o en Martínez 1901, 355.

54 Datos tomados de: http://coria.wn21.com/es/index.php?option=com_content\&view=article\&id=6003\&itemid= $435 \&$ catid $=109$ [consultado el 6/06/2020].

55 Así lo indica HEpOL 18992.

56 Así ILC 65.

57 Medidas ofrecidas en $C I L C C$ IV 1226.

58 Velázquez de Velázquez de Velasco 1753a, f. 15v, nº 5 (transcrito luego por Cornide 1798-1801a y 1798-1801b, f. s/n); Guerra 1840, f. s/n (sin dibujo); Constanzo 1836, 150, no 102 (cf. Cerrillo Martín de Cáceres 2007, 153, nº 102); Viu 1852, 177; CIL II 770; Martínez 1901, 352-353, nº 11; CPILC 225; ILC 49; CILCC IV 1212; HEPOL 21748. 


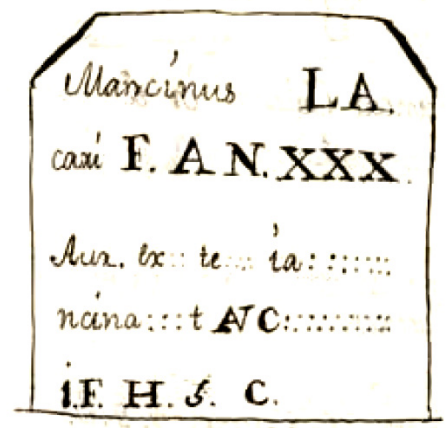

Fig. 4. Inscripción II de Santos Samaniego (Ms. BNE 13078, f. 49).

\begin{tabular}{|c|c|c|c|c|c|}
\hline & $\underline{\text { Santos }}$ & $\underline{\text { Viu }}$ & $\underline{\text { Guerra }}$ & Constanzo & Hübner \\
\hline I.1 & Mancinus LA. & VCINVS L $\cdot \mathrm{P}$. & .......CINVS · LA & LAVCINVS · LEPEARI $\cdot \mathrm{F}$ & $\operatorname{tanCINVS\cdot LA}$ \\
\hline 1.2 & cari F. AN. XXX & CARI $\cdot F \cdot A N \cdot X X X$ & $C A R I \cdot F \cdot A I \cdot X X X$ & $A N \cdot X X X$ & CARI $\cdot F \cdot N \cdot X X X$ \\
\hline 1.3 & Aur ex :: te :::: ia :::::::: & AVR $\cdot E X \cdot T E X \cdot I A \cdot$ & CAVR : EX $\cdot \mathrm{T} \cdot \mathrm{A}$ & AVREX $\cdot T$ & $\mathrm{cAVR} \cdot \mathrm{EX} \cdot \mathrm{T} \cdot \mathrm{tA}$ \\
\hline 1.4 & ncina ::: t ÂNC ::::::::::: & CINA $\cdot$ TAIC & NCINA $\cdot$ T.......... & IANCINA - TANC. & $\mathrm{NCINA} \cdot$ TanCin \\
\hline 1.5 & i. F. H.S.C. & ..................... P . & $\mathrm{I} \cdot \mathrm{F} \cdot \mathrm{H} \cdot \mathrm{S} \cdot \mathrm{E} \cdot$ & $I \cdot F \cdot O \cdot F \cdot O$ & $\mathrm{I} \cdot \mathrm{F} \cdot \mathrm{H} \cdot \mathrm{S} \cdot \mathrm{E}$ \\
\hline 1.6 & & & & $L F \cdot \mid \cdot O$ & \\
\hline
\end{tabular}

Tabla 3. Variantes de lectura de la Inscripción II.

Restitución textual: $[$ Ta]ncinus $\cdot$ La/cari $\cdot f($ ilius $) \cdot$ an (norum) $\cdot X X X \beta$ [C]aur(iensis) $\cdot$ ex $\cdot$ t(estamento) $\cdot[T]$ ancina $/ \cdot T[$ an $] c[$ in $] / i \cdot f($ ilia $) \cdot h($ ic $) \cdot s($ itus $) \cdot e($ st $)$.

Siguiendo la información transmitida por Guerra, ${ }^{59}$ Hübner dice que estaba "en la esquina del muro de la banda del Norte, muy alta e incompleta". En este caso tal localización sí coincide con la ofrecida por Santos Samaniego, pues este nos dice que se encontraba cerca de la anterior, la cual, como vimos, sitúa en este mismo lienzo norte, frente al resto de autores que la localizan en el lienzo oriental. También la vio Viu, aun reconociendo los problemas de interpretación que ofrecía: "Tampoco de esta sacamos en limpio otra cosa que uno de treinta años fue alli sepultado, y que se hizo la lápida ó sepulcro por disposición testamentaria del mismo". Actualmente la inscripción se encuentra en paradero desconocido.

Como apunta Esteban Ortega, si la lectura que ofrece Hübner (tomada de Velázquez, que es la que siguen tanto él mismo como Sánchez Albalá y Vinagre Nevado) es correcta, el antropónimo Lacarus constituiría un unicum. Mientras que Palomar Lapesa sí lo incluye en su relación de nombres prelatinos, ${ }^{60}$ Abascal Palazón lo rechaza por lo fragmentario del texto. ${ }^{61}$ Por su parte, en fechas más recientes el Atlas Antroponímico de la Lusitania Romana considera nuevamente la

59 Guerra reconoce no haber podido leer su texto en 1840, al estar "muy alta, incompleta y medio borrada", indicando que la tomó de "un libro que hay en la contaduría de los canónigos, manuscrito y copiado de otro que hay en el archivo de la secretaría de Estado sobre los prelados de Coria". A este respecto Hübner indica "fortasse liber Fr. F. de Coria", es decir, la obra de Francisco de Coria, datada en 1608. No obstante, y como tendremos oportunidad de mostrar infra (§ 4), hoy podemos considerar que esta identificación dista de ser correcta. Para los manuscritos de contenido epigráfico vistos y consultados por Guerra durante su estancia en Coria, así como para el papel de Constanzo como fuente de Guerra al respecto de la epigrafía cauriense, véase Cerrillo Martín de Cáceres 2007, 14-15 y 169, n. 348.

60 Palomar Lapesa 1957, 75.

61 Abascal Palazón 1994, 48. 
validez de este antropónimo, Lacar(i)us, ${ }^{62}$ si bien Vallejo Ruiz lo tendrá solo como dudoso ${ }^{63}$ Por nuestra parte, consideramos que la lectura de Santos Samaniego, que se distingue de la adoptada en CIL II 770 en pocos detalles, podría venir a corroborar que, efectivamente, la lectura La/cari es correcta.

Dado que actualmente la inscripción se halla en paradero desconocido, podemos volver a destacar la importancia del testimonio de Santos Samaniego, en tanto que no contamos con más datos relativos a sus dimensiones que los ofrecidos por nuestro erudito salmantino: media vara, esto es, algo más de $40 \mathrm{~cm}$ (entendemos que de altura).

\subsection{Inscripción III (Figs. 5-6)}

"Otra entera de media bara de alto, y más de tertia de ancho, que es cuadrada y dice: LACAR/E. VXSO/RE." ${ }^{64}$

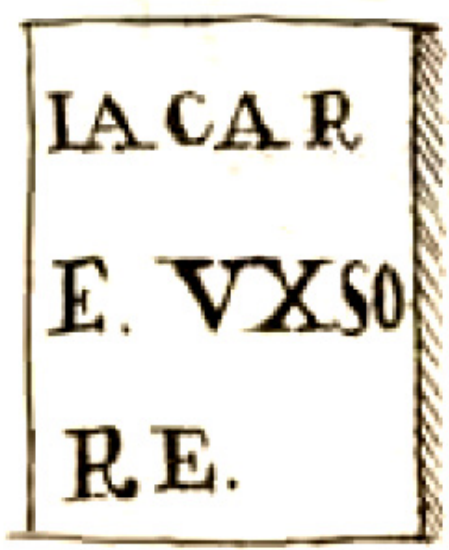

Fig. 5. Inscripción III de Santos Samaniego (Ms. BNE 13078, f. 49).

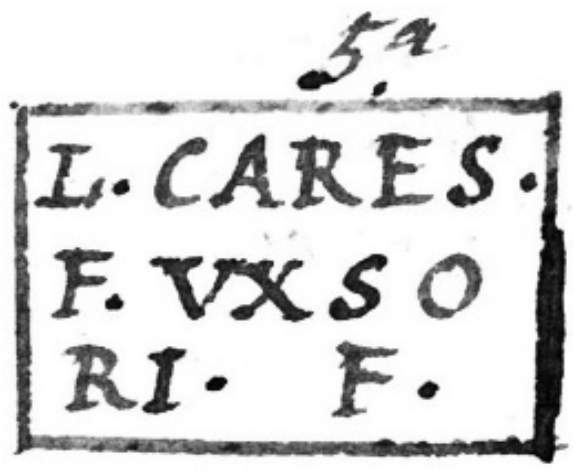

Fig. 6. Dibujo de 1840 de Guerra (RAHCC-9-3931-4/2, f. s/n, inscripción $n^{\circ} 5^{\circ}$ ). (C) Real Academia de la Historia.

\begin{tabular}{|c|c|c|c|}
\hline & $\underline{\text { Santos }}$ & Guerra (1865) & Hübner \\
\hline I.1 & $\overline{\text { LACAR }}$ & L. CARES & \\
\hline 1.2 & E. VXSO & F. VXSO & $\mathrm{L}^{\mathrm{A}} \mathrm{CARES}$ \\
\hline 1.3 & RE. & RI :::: & $\mathrm{F} \cdot \mathrm{VXSO}$ \\
\hline
\end{tabular}

Tabla 4. Variantes de lectura de la Inscripción III.

\footnotetext{
62 Grupo Mérida 2003, 209. Véase, igualmente, su registro en la base ADOPIA Lusitania [http://adopia.humanum.fr/atlas?LACAR(I)VS; consultada el día 5/07/2020].

63 Vallejo Ruiz 2005, 493.

${ }_{64}$ Guerra 1840, f. s/n, no 5, y 1865, 36, nº 8; CIL II 783; CPILC 247; ILC 44; CILCC IV 1207; HEpOL 18985.
} 
Restitución textual: - - - - / L C Cares $(i) ? \cdot / f($ ilius $) \cdot u x s o / r i \cdot f($ ecit $)$.

$\mathrm{Si}$, como recoge Hübner, Guerra situaba esta inscripción "en el muro al principio de la banda norte, cerca de la de Venic $\cdot a \cdot$ Pisit · del Ceán, que no se por qué será más notable que esta", también Santos Samaniego parece apuntar a la cercanía de esta pieza con respecto a su inscripción $n^{0}$ I (esto es, CIL II 790).

Una consecuencia de que todos los autores hayan seguido hasta el presente solo la referencia de Guerra, obviando la mención de Santos Samaniego, es que nada se ha podido precisar acerca de las características de esta inscripción, a la que, por ejemplo, Esteban Ortega se refiere como "Estela de granito de características desconocidas". ${ }^{65}$ Una vez más, Santos Samaniego nos proporciona la única noticia acerca de las dimensiones de este epígrafe, lo cual resulta de gran importancia: "media bara de alto, y más de tertia de ancho" (esto es, ca. 40 x ca. $30 \mathrm{~cm}$ ). De otro lado, conviene destacar que, frente al dibujo de Guerra, en el que la pieza se representa apaisada, las medidas y el dibujo ofrecidos por Santos Samaniego indican que se trataba de una inscripción más alta que ancha (Fig. 5 vs. Fig. 6).

Al margen de la relevancia del testimonio del salmantino para precisar las -hasta ahora desconocidas- características físicas de la pieza, su lectura también reviste importancia, pues se diferencia de la de Guerra, fuente única de quien la toma CIL II $783 \mathrm{y}$, con él, todos los autores que se han referido a ella desde entonces. Tal diferencia estriba en que Santos Samaniego parece registrar aquí, en lín. 1, el mismo antropónimo Lacar(i)us que consta en la incripción precedente, mientras que, por el contrario, la interpunción señalada por Guerra tras la primera letra de esa misma línea ha motivado que la lectura resultante, $L$. Cares(i) $f$., se haya generalizado en la bibliografía (pese a que -y esto resulta sumamente llamativo- ya Hübner plantease lo conveniente de sustituir esta interpunción por una pequeña $\mathrm{A}$, en la misma línea de la lectura de Santos Samaniego). De este modo, se ha llegado a considerar consecuentemente la existencia de un antropónimo Caresius que, por otro lado, constituye un hápax en la onomástica lusitana. ${ }^{66}$ La lectura de Santos Samaniego, por tanto, parece incidir más bien en la existencia de un único nombre, que quizá deba entenderse Lacari, como bien apunta José-Vidal Madruga Flores: se trataría, en consecuencia, del antropónimo Lacar(i)us visto, como hemos comentado, en la inscripción anterior y que, de este modo, encontraría una nueva atestiguación en la epigrafía lusitana. ${ }^{67}$

\subsection{Inscripción IV (Figs. 7-8)}

"A la parte del Oriente, a poca distancia de las antecedentes, se registra una piedra, de dos tertias de alto, y media bara de ancho, que figura y dice:

\section{ITUREVS"68}

65 En CILCC IV 1207.

66 Véase su único registro (considerado como nomen) en la base ADOPIA Lusitania (http://adopia.huma-num.fr/ atlas?CARESIVS, consultado el 8/07/2020).

67 Así consta como posible variante de lectura, según José-Vidal Madruga, en la entrada correspondiente a esta pieza en HEpOL 18985. En las demás lecturas modernas de esta inscripción se mantiene $L$. Cares(i) [http:// eda-bea.es/pub/record_card_2.php?refpage $=\% 2 \mathrm{Fpub} \% 2$ Fsearch_select.php\&quicksearch $=18985 \& \mathrm{rec}=18985$; consultada el 8/07/2020].

68 Versión A: Velázquez de Velázquez de Velasco 1753a, f. 15v, nº 6 (con dibujo); Ponz 1778, 5; Viu 1852, 177; CIL II 788; ILC 63 (con fotografía); HEp 8, 1998, 78a; CILCC IV 1224 (con fotografía, p. 255); HEpOL 18990. 


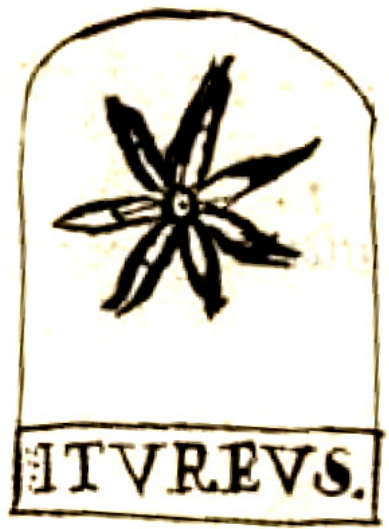

Fig. 7. Inscripción IV de Santos Samaniego (Ms. BNE 13078, f. 49).

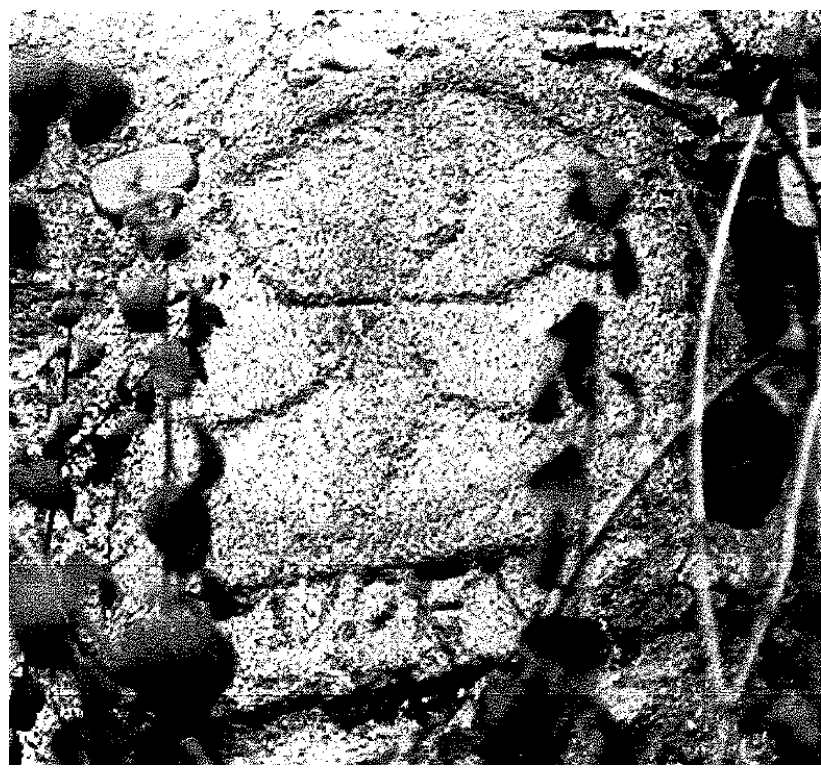

Fig. 8. Inscripción de Tureus (Esteban Ortega 2017, 255).

\begin{tabular}{|c|c|c|c|c|c|}
\hline & $\underline{\text { Santos }}$ & Ponz & $\underline{\text { Viu }}$ & Hübner & Mélida \\
\hline Figura & [estrella hexapétala] & [especie de labor, que parece florón] & [estrella] & [astrum grande] & [media luna] \\
\hline 1.1 & ITVREVS. & T.VREVS & T. VREM & TVREVS & T(ulius) VREVS \\
\hline 1.2 & & & & (línea de fractura) & TAERAN(us) \\
\hline 1.3 & & & & & $A($ nnorum) XLIX \\
\hline 1.4 & & & & & $\ldots$ РО $\cdots$ \\
\hline 1.5 & & & & & $\ldots \ldots$ \\
\hline 1.6 & & & & & $\ldots \ldots$ \\
\hline
\end{tabular}

Tabla 5. Variantes de lectura de la Inscripción IV. 
Restitución textual (versión A): Tureus / - - - - - .

Restitución textual (versión B): T·ureus / Taerai ß a (nnorum) $X$ XLIX/ [- - - ]po [- - - ] / - - . - - / - . - - .

De todas las transmitidas por Santos Samaniego es quizá esta inscripción, correspondiente a una estela de cabecera semicircular, la que plantea más problemas, ya que la investigación se ha referido a ella bajo dos versiones (A y B), planteándose la duda de si nos hallamos ante dos lecturas diferentes de una misma inscripción, o bien ante dos inscripciones distintas. El hecho de que solo una de ellas (CIL II 788 = versión A) se haya conservado hasta la actualidad, impide solventar esta cuestión con seguridad.

El texto registrado por Santos Samaniego ha de vincularse sin duda con la versión A, que corresponde a la transmitida por todos los autores hasta principios del siglo $\mathrm{XX}$, por más que nuestro autor sea el único que lea una $I$ inicial al principio de la primera (y única) línea conservada, rasgo que, hemos de admitir, la fotografía que de ella nos ha llegado no permite apreciar.

Fue a comienzos del siglo XX, como se indicó, cuando Mélida ofreció una nueva -y más amplia- lectura (versión B), aun identificando la inscripción, de todos modos, con CIL II 788. La identificación entre ambas inscripciones será asumida por Hurtado San Antonio y también por Sánchez Albalá y Vinagre Negado, si bien de forma contradictoria, pues primero (ILC 63, donde sí citan a Santos Samaniego) consideran errónea tal identificación y, justo a continuación (ILC 64), defienden que las dos inscripciones son solo una:

Según Mélida la parte superior de esta lápida es semicircular, destacando en la cabecera un cuarto creciente lunar. Reseñar que tanto Mélida como Hurtado han asimilado esta lápida con la 788 de CIL II, no siendo cierto ya que Hubner indica que en la parte superior hay un astro grande (estrella) y señala una línea de corte bajo el primer renglón que es el único, y lo transcribe como TVREVS, localizándola en la muralla. Esta lápida [ILC 64] es sin duda la anterior de nuestro estudio. ${ }^{69}$

Finalmente, Esteban Ortega considerará que nos hallamos ante dos inscripciones diferentes (CILCc IV 1224 y 1225), aun reconociendo que no ha podido localizar la primera (como sí hicieran Sánchez Albalá y Vinagre Nevado, que la identificaron aún en la muralla) y que la segunda se halla igualmente perdida.

Al igual que Santos Samaniego, también Velázquez, Ponz o Viu indican que la inscripción (versión A) se hallaba en las murallas. Posteriormente, y al ofrecer su versión (la B, que, insistimos, identifica con CIL II 788), Mélida señala ya que "hállase en aprovechado como losa en la acera correspondiente a los números pares, en la calle del Horno". ${ }^{70}$ Si realmente Mélida la vio personalmente (como parece deducirse de las medidas que ofrece, aspecto sobre el que volveremos infra) y en el suelo, estaríamos ante dos inscripciones indudablemente distintas. Pero no deja de sorprender que solo y

${ }_{69}$ Sánchez Albalá y Vinagre Nevado, en ILC 64. Ya Mantas 2002, 282, se hace eco de esta duplicidad que presentan Sánchez Albalá y Vinagre Nevado para ILC 63 e ILC 64, considerando que "teria sido mais correcto atribuir-lhes o mesmo número e tratar no comentário da questão da duplicação". También el equipo técnico de la revista Hispania Epigráfica (en comentario a HEp 8, 1998, 78a-b) parecerá compartir esta identificación entre ambos textos, teniéndolos por dos versiones distintas - $a$ y $b$ - de la misma inscripción $H E p$ 8, 1998, 78.

70 Mélida 1924, 308. 
exclusivamente Mélida reconozca haberla visto - de hecho, de él beben cuantos autores mencionan esta versión- y que ningún investigador dé cuenta de su existencia: ni en esta acera ni, con este mismo texto, en las murallas de Coria.

Ambas versiones parecen compartir la forma semicircular de su cabecera, por lo que, a tenor exclusivamente del texto transmitido para la lín. 1, quizá pudiera plantearse que la versión A no correspondiese sino a la parte superior y fragmentaria de una inscripción más larga -versión B-. Sin embargo, de acuerdo con la versión A aparecería decorada con una flor o estrella, tal y como indica Santos Samaniego (quien dibuja una flor heptapétala, cuando hoy sabemos por la fotografía-Fig. 8- que en realidad es hexapétala) y recogen también Velázquez (quien, precisamente, en su relación de los epígrafes caurienses solo ofrece dibujo de esta inscripción) ${ }^{71}$ y Ponz. Por el contrario, y para la versión B, por él mismo inaugurada, Mélida indica que esta pieza presentaba su cabecera decorada no con una flor, sino con una media luna.

Por lo que respecta a las medidas, parecen ser igualmente reveladoras. Para la versión A, Santos Samaniego aporta unas dimensiones aproximadas de unos $55 \mathrm{~cm}$ (dos tercios de vara) de altura por $41 \mathrm{~cm}$ (media vara) de ancho, medidas que, en principio, no se ajustan a las indicadas por la bibliografía más reciente: (38) x 47 cm. ${ }^{72}$ Sin embargo, a la vista de la fotografía (Fig. 8), que certifica la fidelidad del dibujo de Santos Samaniego (Fig. 7), resulta obvio que la pieza es más alta que ancha, y no al revés, como se deduce de las medidas aportadas por ILC y CILCC. Por su parte, para la versión B, Mélida (y con él cuantos contemplan esta versión) $)^{73}$ transmite unas medidas de $95 \mathrm{~cm}$ de altura por $47 \mathrm{~cm}$ de anchura, cifras de las que sí se deduce un formato vertical como el apreciable en la versión A, pero que, a la vista de la fotografía moderna de esta estela, arroja una altura que nos parece excesiva.

En suma, creemos que, pese a la parquedad del testimonio de Santos Samaniego, los datos que del mismo se deducen (texto, localización, decoración y medidas, por más que estas sean aproximadas) permiten reforzar la idea de que nos hallamos no ante la parte superior de la inscripción vista y transcrita luego por Mélida, sino ante un epígrafe distinto y que, por tanto, debe ser efectivamente considerado de forma diferenciada.

\subsection{Inscripción V (Figs. 9-10)}

"Assimismo se registra en la parte del Oriente en uno de los muros de la muralla otra pieza de cinco quartas de largo y dos tertias de ancho quadrada que dice:

\section{AN. XI. AVRIAVII.. i.. / A. ALBINI · T:AN :::::: EST • / ET SATVRNIN ::::::: / EX TESTAMENT::::::}

De modo que el primer renglon, que tiene otra piedra antes del que se figura, está truncado a la larga" 74

71 Llegados a este punto, hemos de destacar también que, de entre todos los epígrafes relativos a Coria registrados por Velázquez, es justo este el único que Cornide dejará sin transcribir al transmitir los comentarios del malagueño referentes a Coria (Cornide 1798-1801a y 1798-1801b).

72 ILC 88 y CILCC IV 1224.

73 Mélida 1924, 308; ILC 64 y CILCC IV 1225.

74 Velázquez de Velasco 1753a, f. 15v, no 3 (transcrito luego por Cornide 1798-1081a y 1798-1801b, f. s/n); Ponz 1778, 54, no 3; Ceán Bermúdez 1832, 409; Guerra 1840, f. s/n, nº 1; Viu 1852, 176; Guerra 1865, 35, nº 3; CIL II 771; Thouvenot 1940, 229; CPILC 223; Armistead 1985, 157, n. 5; ILC 18 (con fotografía); CILCC IV 1186 


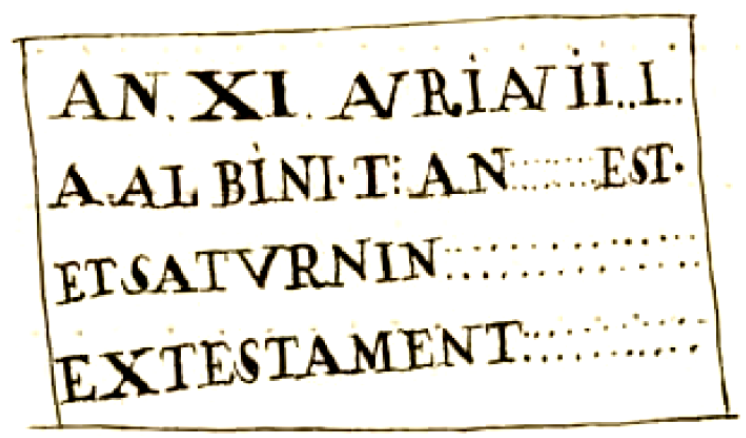

Fig. 9. Inscripción V de Santos Samaniego (Ms. BNE 13078, f. 49).

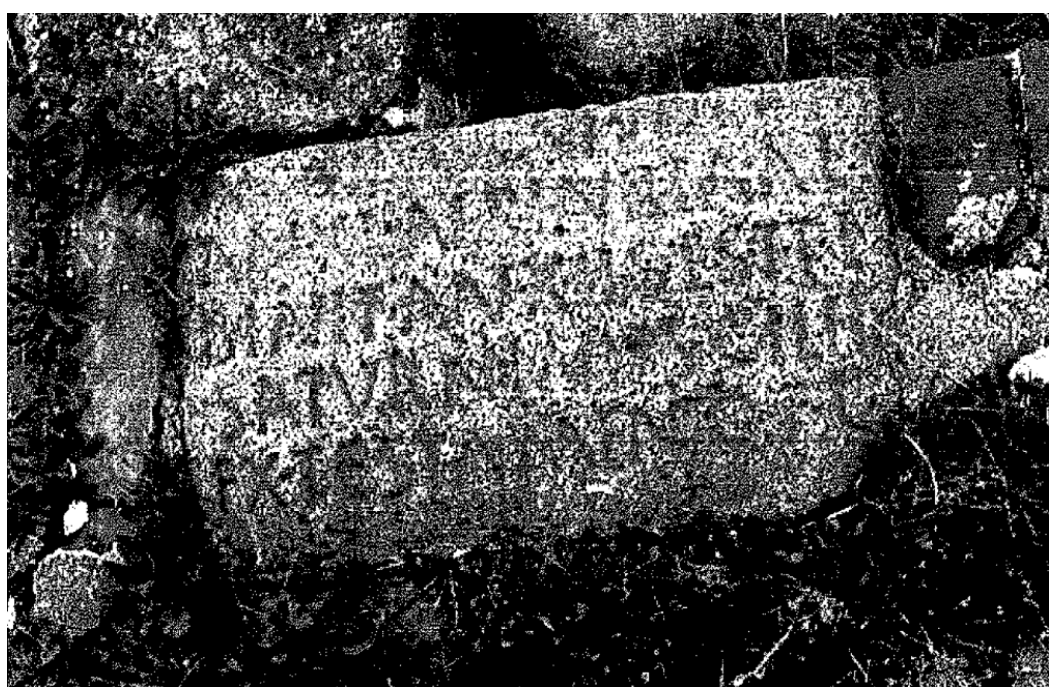

Fig. 10. Epígrafe funerario de Aunia y Albinilla (Esteban Ortega 2017, 236).

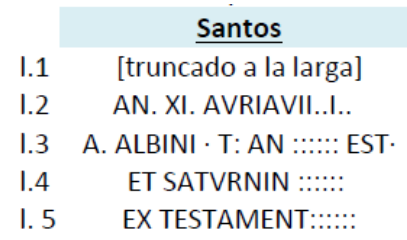

Velázquez
ALB...
AN XL ALBINILLA AL
BINI F AN X H S E S T T L
SATVRNINVS
EX TESTAMENTO F C

Ponz
ALB..................
AN. XL. ALBINILLA, AI
BINI. F. AN. X. H. S. E. S. T. T. L.
SATVRNINVS
EX TESTAMENTO. F. C.

Guerra (1840)
$\quad[\ldots \ldots]$
$:$ : : : ALBINILLA $\cdot$ AL
$\cdot \mathrm{F} \cdot \mathrm{AN} \cdot \mathrm{X} \cdot \mathrm{H} \cdot \mathrm{S} \cdot \mathrm{E} \cdot \mathrm{S} \cdot \mathrm{T} \cdot \mathrm{T} \cdot \mathrm{L} \cdot$
$\mathrm{SATVRNINVS} \cdot \mathrm{CILI} \cdot \mathrm{F}$
. TESTAMENTO $\cdot \mathrm{P} \cdot \mathrm{C} \cdot$

\begin{tabular}{|c|c|c|}
\hline & Viu & Hübner \\
\hline I.1 & ALB $\cdots \cdots \cdots \cdots \cdots \cdots \cdots$ & 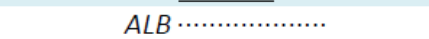 \\
\hline 1.2 & $A N \cdot X L \cdot A L B I N I L I A \cdot A L$ & $A N \cdot X L \cdot A L B I N I L L A \cdot A L$ \\
\hline 13 & $\mathrm{NINI} \cdot \mathrm{F} \cdot \mathrm{AN} \cdot \mathrm{X} \cdot \mathrm{H} \cdot \mathrm{S} \cdot \mathrm{E} \cdot \mathrm{S} \cdot \mathrm{T} \cdot \mathrm{T} \cdot \mathrm{L}$ & $\mathrm{BINI} \cdot \mathrm{F} \cdot \mathrm{AN} \cdot \mathrm{XH} \cdot \mathrm{S} \cdot \mathrm{E} \cdot \mathrm{S} \cdot \mathrm{T} \cdot \mathrm{T} \cdot \mathrm{L}$ \\
\hline 1 & SATVRNINVS & SATVRNINVS $\cdot \mathrm{CI} / \mathrm{I} \cdot f$ \\
\hline I. 5 & EX $\cdot$ TESTAMENTO $\mathrm{F} \cdot \mathrm{C}$ & EX $\cdot$ TESTAMENTO $\cdot \mathrm{P}$ \\
\hline
\end{tabular}

Tabla 6. Variantes de lectura de la Inscripción V. 
Restitución textual: Aunia Iucundi $f($ ilia $) \cdot /$ an (norum) $\cdot X L \cdot$ Albinillla $\cdot$ Al/bini $\cdot$ $f($ ilia) $\cdot$ an (norum) $X L \cdot h($ ic) $s($ ita $) \cdot e(s t) s($ it $) t($ ibi $) \cdot t($ erra $) \cdot l($ evis $) \cdot /$ Saturninus $\cdot$ Cili $\cdot f$ (ilius) / ex $\cdot$ testamento $\cdot f($ aciendum) c(uravit) .

CIL II 771 toma esta inscripción de Velázquez, Ponz y Guerra. Según Velázquez estaba en la muralla, donde también la vio Santos Samaniego quien, en esta ocasión, ofrece la versión más alejada de la lectura correcta. Sin embargo, una vez derribado el tramo de la muralla en que se insertaba, la inscripción desapareció. En la bibliografía específica es frecuente datar la desaparición del epígrafe en 1838, momento en que se destruyó la torre en que se hallaba embutida. Así lo indican, entre otros, Sánchez Albalá y Vinagre Nevado, aun sin especificar a quién deben esta información, ${ }^{75} \mathrm{y}$, más recientemente, Esteban Ortega, quien remite para ello a Ponz: "Según Ponz 'se hallaba hasta el verano de 1838 en la esquina de un cubo del lienzo oriental del muro; al deshacerse desapareció" ". ${ }^{76}$ Sin embargo, resulta evidente que la referencia es a todas luces errónea, no solo porque Ponz la sitúa ciertamente aún en las murallas, sino, sobre todo, por el mismo hecho de que, dada la fecha de su trabajo (1788), no pudo hacer referencia a la demolición de la torre en 1838.

En realidad, es a Guerra (quien parece no haber visto personalmente la inscripción, pese a haber estado en Coria "desde Octubre de 1833 hasta fines del año de 1838" "77) a quien debemos la noticia del derribo de esta torre y la deslocalización resultante de esta inscripción. Además, y tomando los datos de Constanzo, ofrece una restitución textual más larga que la que él mismo (así como el resto de autores que sobre ella han tratado) recogiese al dar la descripción de esta pieza:

La $1^{\text {a }}$ inscripción está en una piedra berroqueña encannada, que se hallaba en la esquina de un cubo del lienzo oriental del muro, hasta el verano de 1838 en que deshicieron dicho cubo, y no sé donde pusieron aquella piedra. D. Claudio Constanzo, vecino de Cáceres, e individuo de la Academia de la Historia, la trae en un cuaderno de su puño, que me ha enseñado, de este modo: Cresceneus Albinus $=$ P. et Atilia f. III an. XL = Albinila Albini f. an. $X=$ h.s.e.s.t.t.l. $=$ saturninus $C I I I I$ $=$ ex testamento. ${ }^{78}$

Pese a ello, posteriormente, en sus notas a la obra de Viu, datadas en 1865, Guerra la vuelve a situar todavía en el lienzo oriental de la muralla, basándose en esta ocasión -como él mismo reconoce- en un trabajo previo de Constanzo, lo que pudo motivar la confusión. ${ }^{79}$

75 "reseña de localización que aparece en todos los textos sobre epigrafía” (Sánchez Albalá y Vinagre Nevado, en ILC 18).

76 Esteban Ortega, en CILCC IV 1186.

77 Guerra 1865, 135.

78 Guerra 1840, f. $\mathrm{s} / \mathrm{n}, \mathrm{n}^{\mathrm{o}} 1$. Aunque dada la fórmula con que se inicia la parte conservada del texto de esta inscripción parece claro que haría falta la adición, cuando menos, de una primera línea inicial, solo Santos Samaniego se hace eco explícitamente del hecho de que faltaría la parte inicial de la inscripción al referir que el inicio de su texto se hallaba "truncado a la larga". Lo cierto es que el texto de esta primera línea que nos transmite Constanzo - a través de Guerra- en nada se parece a la restitución actual del texto de la pieza debida a Armistead (1985, 157, n. 5) tras su redescubrimiento y que nos ofrecen Sánchez Albalá y Vinagre Nevado (en $I L C$ ) o Esteban Ortega (en CILCC IV).

79 No deja de sorprender, sin embargo, que, pese a las referencias de Guerra (1840, f. s/n, y 1865, 35), en el apartado dedicado a Coria en la obra de Constanzo (cf. Cerrillo Martín de Cáceres 2007, 170-175), esta inscripción ciertamente no aparece. 
Tal confusión se acentuaría de atender a las palabras de Ceán Bermúdez que, en su célebre Sumario, editado en 1832, indica que esta inscripción se encontraba "en el palacio del señor del pueblo". ${ }^{80}$ No obstante, y como hemos tenido ocasión ver (véase supra, § 3.1), Ceán Bermúdez interpreta de modo erróneo los datos ofrecidos por Ponz.

Lo cierto es que después de 1838, año en que la inscripción parece haber sido extraída de las murallas, ya Viu nos dice también que "está sobre la pared de una casa particular", aunque reconoce no haberla visto personalmente, presentando los problemas de transmisión textual:

En esta inscripción, que está sobre la pared de una casa particular, vemos una equivocación, pues el $\mathrm{H} \cdot \mathrm{S} \cdot \mathrm{E} \cdot \mathrm{S} \cdot \mathrm{T} \cdot \mathrm{T} \cdot \mathrm{L}$ no concuerda con el plural de las dos personas que cubría la lápida, á saber: el Albino ó Albina de edad de cuarenta años, y la otra Albinilia de diez. Seguros estamos moralmente de que en el original no hay tal discordancia; pero no queremos variaría, puesto que hablamos solo de referencia, no habiéndola visto personalmente. Este defecto de la inexactitud de las copias, acogido sin examen por los mismos anticuarios de nota, hacen á veces ininteligible el sentido. ${ }^{81}$

Más tarde Thouvenot la reencontró, junto con otra inscripción de la localidad, ${ }^{82}$ "sur la terrasse d'une maison particulière où elles avaient été remployées". ${ }^{83} \mathrm{Su}$ información será completada por Armistead, quien señala que se hallaba "en el patio de la casa de la viuda de Benigno Gutiérrez (actualmente bar-restaurante 'El Mesón', en la calle Gabriel y Galán, antigua calle 'del Cuerno')" ${ }^{84}$ formando parte de una especie de banco de piedra y ladrillos. Allí la localizan en 1998 Sánchez Albalá y Vinagre Nevado y, en 2017, también Esteban Ortega, si bien este último autor indica que no pudo acceder personalmente a ella.

Por ello las medidas que Esteban Ortega aporta para esta pieza (54 x 94 x $36 \mathrm{~cm})$ se basan en el estudio previo de Sánchez Albalá y Vinagre Nevado, dimensiones de nuevo ciertamente aproximadas a las aportadas en su momento por Santos Samaniego ("cinco quartas de largo y dos tertias de ancho", esto es, $c a .104$ x $56 \mathrm{~cm}$ ) quien, recordemos, no la vio de cerca, como hicieran ya Sánchez Albalá y Vinagre Nevado, sino cuando aún estaba inserta en la muralla de la localidad.

\subsection{Inscripción VI (Figs. 11-12)}

"Otra a la parte del norte, que tiene dos tercias de largo y media bara de ancho. Cortada por los renglones y no se distingue mas que lo que se figura:

80 Ceán Bermúdez 1832, 409.

81 Viu 1852, 176. También Thouvenot $(1940,229)$ llamó la atención sobre la falta de concordancia entre el número de difuntos y la fórmula funeraria final, reconociendo igualmente Esteban Ortega que "la fórmula funeraria no se corresponde con la propia de un epitafio doble, sino sencillo".

82 CILCC IV 1215 (=HEPOL 23295).

83 Thouvenot 1940, 229.

84 Armistead 1985, 157, n. 5. 
VREVS. CAI.C/ NIS. F. AN::::::::/ H. S. EST :::::

Y aunque se reconoce a ver algunas letras, no se perciben, más que las figuradas" ${ }^{85}$

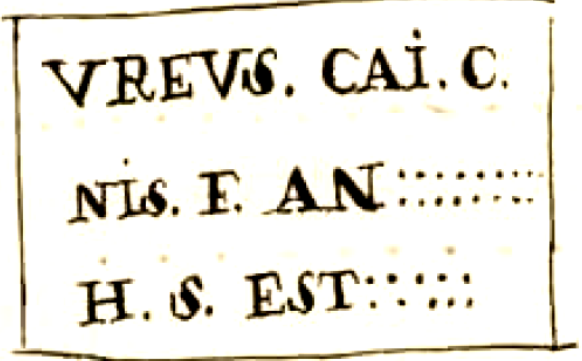

Fig. 11. Inscripción VI de Santos Samaniego (Ms. BNE 13078, f. 49).

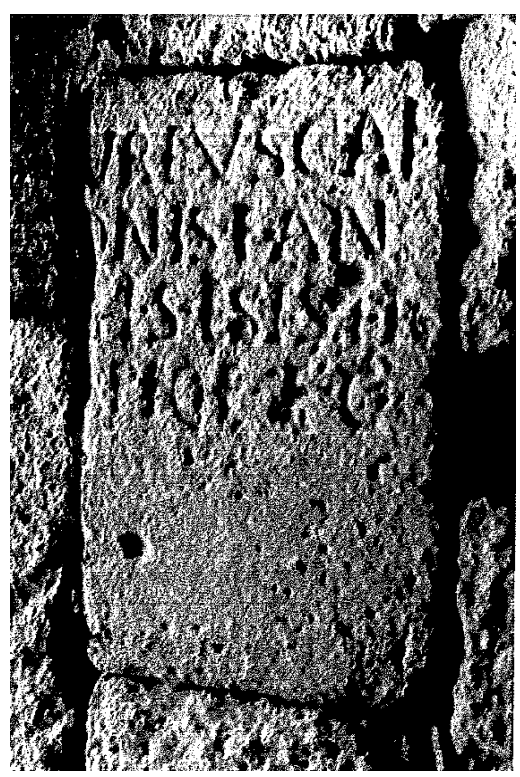

Fig. 12. Epitafio de Tureus (Esteban Ortega 2017, 258).

\begin{tabular}{|c|c|c|c|}
\hline & $\underline{\text { Santos }}$ & $\underline{H A E} \underline{2213}$ & Sánchez-Albalá \\
\hline I.1 & VREVS. CAI. C & VR $\cdot$ FVSCA & [T]VREVS CAI \\
\hline 1.2 & NIS. F. AN:::::::: & $\cdot \mathrm{N} \cdot \mathrm{HISPAN}$ & {$[N] O N I S \cdot F($ ilius $) \cdot A N($ norum) } \\
\hline 1.3 & H. S. EST ::::: & $\mathrm{H} \cdot \mathrm{S} \cdot \mathrm{EST} \cdot \mathrm{S} \cdot \mathrm{T} \cdot \mathrm{T} \cdot \mathrm{L}$ & {$[---] H($ ic $) \cdot S($ itus $) \cdot E S T \cdot S($ it $) \cdot T($ ibi $) \cdot T($ erra $) \cdot L($ evis $)$} \\
\hline 1.4 & & $\mathrm{PIOF} \cdot \mathrm{F} \cdot \mathrm{C}$ & $\mathrm{PIO} \cdot \mathrm{F}($ rater $) \cdot \mathrm{F}($ aciendum $) \cdot \mathrm{C}($ uravit $)$ \\
\hline
\end{tabular}

Tabla 7. Variantes de lectura de la Inscripción VI.

Restitución textual: [T]ureus Cai/[n]onis $\cdot f($ ilius $) \cdot$ an(norum) $\cdot /[$-c.1-2-] h(ic) $\cdot s($ itus $) \cdot e s t \cdot s($ it $) \cdot t($ ibi $) \cdot t($ erra $) \cdot l($ evis $) /[$-c.1-2-]pio $\cdot f($ rater $) \cdot f($ aciendum $) \cdot$ c(uravit) $\cdot$

Aunque, como vemos, ya Santos Samaniego hace referencia a este epígrafe a mediados del siglo XVIII, lo cierto es que este pasó desapercibido para la investigación epigráfica durante siglos. La pieza es publicada por vez primera en 1965, y como inédita, gracias a una comunicación de Díaz Martos que fue recogida en $H A E$ 2213, de donde la copió directamente Hurtado San Antonio (CPILC 809). Sin embargo, la primera edición completa de esta inscripción no será publicada hasta 1998 (ILC 67). ${ }^{86}$ Los autores del corpus epigráfico cauriense sí que citarán ya como fuente a la obra de Santos Samaniego, comunicando, asimismo, que la pieza se encuentra aún

\footnotetext{
HAE 2213; CPILC 809; ILC 67 (con fotografía); HEp 8, 1998, 79; CILCC IV 1228 (con fotografía, p. 258); HEPOL 23423.

86 Citada previamente en Saponi Sergio 1988, 69, $\mathrm{n}^{\circ} 34$.
} 
en el lienzo nororiental de la muralla (calle de la Corredera), donde hace cerca de tres siglos la viese ya nuestro ilustrado autor. ${ }^{87}$

La lectura transmitida por Santos Samaniego presenta un elevado grado de acierto resultando, pese a la extraña distribución del texto en líneas 1-2, mucho más cercana al texto real que la transmitida por Díaz Martos, de quien dependió, como hemos señalado, su publicación y conocimiento. Visto que los sencillos dibujos del autor se acomodan a las formas reales de los epígrafes, cuando estos se conservan o se posee fotografía para efectuar el cotejo, resulta también extraña la forma que transmite: la falta de la línea final parece indicar que algún tipo de obstáculo impedía, en su momento, la visión completa de la pieza.

Por otro lado, si comparamos las medidas dadas para la pieza por Sánchez Albalá y Vinagre Nevado (seguidas luego por Esteban Ortega), de 66 x (43) cm, con las ofrecidas por Santos Samaniego, dos tercios de largo $(55 \mathrm{~cm})$ y media vara de ancho $(42 \mathrm{~cm})$ veremos que la coincidencia en la anchura es casi exacta, mientras que las diferencias en cuanto a la altura pueden responder al extremo que acabamos de plantear. Se mostraría así, una vez más, la fiabilidad de este autor en cuanto a la descripción de las inscripciones caurienses por él anotadas.

\section{Hübner, Guerra y Francisco de Coria}

Como ya tuvimos oportunidad de señalar supra (§ 3.2, Inscripción II), al respecto de CIL II 770 Hübner apunta que, para la versión que de esta inscripción transmite en su manuscrito de $1840,{ }^{88}$ Guerra -quien, como vimos igualmente, reconoce no haber visto personalmente la pieza- pudo haber manejado la obra de Francisco de Coria, con la que también sospecha podría vincularse el registro de CIL II 791, en este caso transmitido por Céan Bermúdez.

Resulta muy interesante que Hübner señale, en la praefatio del apartado del CIL II dedicado a Coria, ${ }^{89}$ que ni él ni Enrique Flórez encontraron estas dos inscripciones en el ejemplar que el propio Flórez tenía a su disposición de la obra Francisco de Coria, la ya citada Descripcion Historica y general de la Provincia de Extremadura. Sin embargo, de ella depende, de manera indudable, el ya citado epígrafe correspondiente a CIL II 802, de Villanueva de la Sierra (integrado en el territorio de la antigua Caurium).

Una vez más, se pone de relieve aquí la necesidad de cotejar las diferentes copias manuscritas de una misma obra, ${ }^{90}$ pues, en efecto, no siempre todas están completas. Así debía ocurrirle a la copia que poseía Flórez pues, tanto en el ejemplar de la

\footnotetext{
Más recientemente, Esteban Ortega (en CILCc IV 1228) la sigue situando en el mismo lugar.

Esto es, el correspondiente a RAH-CC-9-3931-4/2.

Cf. CIL II, p. 97.

Al respecto de la obra de Francisco de Coria, el propio Hübner remite a Muñoz y Romero quien, efectivamente, registra: "MS, en 4", en la Biblioteca Columbina y en la Academia de la Historia, en la biblioteca de la España Sagrada, y en biblioteca de la Universidad de Valladolid” (Muñoz y Romero 1858, 117; s.v. Extremadura, $\mathrm{n}^{\mathrm{o}} 1$ ). El manuscrito de la Real Academia corresponde a la signatura 9-5029 [https://www.yumpu.com/es/document/ $\mathrm{read} / 14084454 /$ catalogo-general-de-manuscritos-real-academia-de-la-historia; consultado el día 6/06/2020]. Lo cierto es que en realidad son bastantes más (un total de siete) las copias que de esta obra nos han llegado hasta el presente [véase https://biex.juntaex.es/biex/noticia/view.action?id=367; consultado el 9/07/2020].
} 
Universidad de Valladolid (incompleto), ${ }^{91}$ como en el ejemplar que ingresó no hace muchos años en la Biblioteca Nacional de España, y que parece ser el original, ${ }^{92}$ puede comprobarse que, efectivamente, Francisco de Coria sí llegó a recoger el epígrafe correspondiente a CIL II $791,{ }^{93}$ así como CIL II $802 .{ }^{94}$ Sin embargo, a no ser que haya escapado a nuestro cotejo, en ninguna de las dos versiones consultadas de la obra de Francisco de Coria se constata referencia alguna a CIL II 770.

Llegados a este punto, y partiendo de esta ausencia de CIL II 770 de la obra de Francisco de Coria, es necesario destacar un aspecto que pudiera revestir de gran importancia: que las variantes de lectura que Hübner atribuye a Guerra en CIL II $770^{95}$ no solo no parecen concordar con la lectura que, de esta inscripción, nosotros tomamos personalmente en el manuscrito del propio Guerra de la Real Academia (Tabla 3), sino que sorprendentemente coinciden, prácticamente letra a letra, con la lectura que de este epígrafe transmite Santos Samaniego. A partir de esta coincidencia, cabría plantear dos posibilidades:

a) Que la obra de la que bebe Guerra al respecto de CIL II 770 pudiera haber sido en realidad la de Santos Samaniego, dada la imposibilidad de seguir manteniendo que la fuente original fuese Francisco de Coria. De esta forma, la fuente que es descrita por Guerra bajo los términos de "un libro que hay en la contaduría de los canónigos, manuscrito y copiado de otro que hay en el archivo de la secretaría de Estado sobre los prelados de Coria" podría haber sido la de nuestro erudito salmantino. A este respecto, es de lamentar que los autores del primer corpus de epigrafía de Coria -quienes, como ya destacamos en su momento, fueron los primeros en recuperar a Santos Samaniego como fuente para la epigrafía cauriense-, al citar al autor del siglo XVIII, ${ }^{96}$ no lleguen a precisar la procedencia del documento que manejan, por si pudiera caber la posibilidad de que exista, en otra biblioteca, otra copia de las Memorias de Santos Calderón, habiendo sido esta la consultada en su día por Guerra.

b) Que Guerra no usó como fuente directa a Santos Samaniego, sino que tanto uno como otro bebieron de otro documento, de una tercera fuente (pudiendo descartar ya que se tratase de Francisco de Coria). ${ }^{97}$ A este respecto puede resultar interesante señalar que, si bien Santos Samaniego suele dar los textos de las inscripciones en mayúsculas (Figs. 5, 7, 9 y 11), únicamente en su Inscripción I (Fig. 3), pero de manera mucho más evidente, precisamente, en su Inscripción II (=CIL II 770, Fig.

91 Se conserva, con la signatura Ms. U/Bc Ms 079, formando parte del Fondo Antiguo de la Universidad de Valladolid.

92 Ms. BNE 23.044, del que, en el Registro del Catálogo, online, puede leerse: "Compra Luis Crespí de Valldaura Madrid 2001". El manuscrito no se encuentra registrado en el catálogo de Hernando Sobrino pues, para su confección, revisó los inventarios correspondientes a los manuscritos n ${ }^{\circ} 1$ a 23.000 (Hernando Sobrino 2009, 23). Debemos, no obstante, el conocimiento de este manuscrito a la propia autora.

93 Coria 1608, Ms. U/Bc Ms 079, f. 148v; Ms. 23.044, f. 89v.

94 Coria 1608, Ms. U/Bc Ms 079, f. 149r/v; Ms. 23.044, f. 89v.

95 Lín. 1: Mancinus; lín. 3: AVR $\cdot$ EX : : T: : IA; lín. 4: NCINA $::$ TNC : :

96 Sánchez Albalá y Vinagre Nevado 1998, 129. Tampoco Esteban Ortega 2017, 201, pese a incluir la referencia a Santos Samaniego (=Calderón de la Barca) en la bibliografía final de su corpus, señala la procedencia del documento, si bien el hecho de que Santos Samaniego únicamente aparezca en la bibliografía final de la obra, y no en ninguna de las entradas correspondientes a las inscripciones por él transmitidas (CILCC IV 1186, 1207, $1212,1224,1226$ y 1228) permite pensar que el autor no llegó a consultar directamente la obra de nuestro erudito salmantino.

97 Al respecto de los manuscritos de contenido epigráfico utilizados como fuente por Guerra para la epigrafía de Coria -con un importante papel en este sentido de Constanzo- remitimos de nuevo a Cerrillo Martín de Cáceres $2007,14-15$ y 169, n. 348 . 
4) utilice las minúsculas en parte de sus transcripciones ¿Podría esto indicar que, en estas inscripciones, Santos Samaniego, no vio directamente las letras que escribe en minúscula y que, en consecuencia, las restituyó a partir de otra fuente?

Con la documentación disponible, nada seguro podemos apuntar a este respecto. Pero la relación entre Santos Samaniego y Felipe L. Guerra al respecto de la epigrafía cauriense, y sobre todo en lo relativo a CIL II 770, se nos antoja como una posibilidad cuando menos sugerente.

\section{A modo de conclusión}

A diferencia de eruditos contemporáneos como Velázquez, o de otros posteriores que visitaron Coria movidos por un interés específico en sus antigüedades, en general, o en sus inscripciones, en particular, Santos Samaniego fue un erudito cuyo trabajo, como tuvimos oportunidad de ver, estuvo enmarcado en un proyecto concreto (la Comisión de Archivos) y, por lo mismo, guiado por una finalidad bien distinta (la recopilación y estudio de documentos de interés para la Historia Eclesiástica en los archivos de la catedral). No obstante, fiel al clima favorable al estudio y recopilación de epígrafes imperante en su momento (del que también participó, y mucho, el padre Burriel, director de la Comisión) ${ }^{98}$ no perdió la oportunidad de tomar nota, como también hicieran otros comisionados,${ }^{99}$ de las inscripciones romanas de la localidad en que desempeñó su encargo. Unas notas que, en efecto, carecen de conexión alguna con el contenido general de su crónica de la historia del obispado de Coria.

En sus apuntes epigráficos, que parecen tomados a vuelapluma, Santos Samaniego centra su atención en los soportes de las distintas inscripciones romanas que identificó, señalando escueta, pero correctamente, su forma y decoración (expresadas ambas en los dibujos), así como sus medidas y localización (en el texto). Como hemos tenido oportunidad de mostrar, sus dibujos se revelan muy correctos (compárense, a este respecto, las ilustraciones de las Inscripciones I, IV o V -Figs. 2, 7 y 9- con las fotografías actuales de las piezas -Figs. 3, 8 y 10-), sus cálculos de las medidas muy aproximados y exactas las referencias a la posición de los epígrafes en las murallas de la ciudad.

De este modo, su testimonio es de gran utilidad para complementar las informaciones aportadas por los otros eruditos, tanto contemporáneos como posteriores, que trataron sobre la epigrafía de Coria. ${ }^{100}$ Ello es especialmente cierto en el caso de las inscripciones que en la actualidad se encuentran perdidas, como las Inscripciones II y III: para ambas, Santos Samaniego nos proporciona una valiosísima

Véase Hernando Sobrino 2017, 39-46.

Como Ascensio de Morales, entre otros; véase Hernando Sobrino 2009, 80-81, con la bibliografía previa.

100 Esto se hace evidente, por ejemplo, al confrontar el carácter de los datos aportados por Santos Samaniego con la parte dedicada a la epigrafía de Coria por parte de Claudio Constanzo (cf. Cerrillo Martín de Cáceres 2007, 170-175). Y es que si Santos Samaniego incide sobre todo en las características formales, Constanzo se centrará eminentemente en el contenido textual de las distintas inscripciones que transcribe -llegando a dar su traducción-, sin indicar en cambio la situación concreta de las piezas en las murallas de la localidad (solo para el caso de CIL II 776 Constanzo menciona que se trataba de una "lápida en un Muro sobre el Arco de la Puerta de la Guia" -cf. Cerrillo Martín de Cáceres 2007, 170, n 96-, mientras que para el resto de las inscripciones caurienses por él tratadas, las referencias a su situación se limitan a la escueta mención "en Coria en la Muro" sin más detalles) y sin ofrecer, ni siquiera de forma aproximada, sus dimensiones. 
información sobre las características formales de las piezas y sus dimensiones. No obstante, sus notas han sido igualmente valiosas para concretar ciertos aspectos confusos y sujetos a discusión relacionados con piezas conservadas. Así ha ocurrido, por ejemplo, con la Inscripción I, para la que la información aportada por Santos Samaniego permite descartar que se hallase decorada con dos retratos o cabezas (aspecto este confirmado por los más recientes análisis de la pieza: ILC y CILCc IV) y situada en la Puerta de la Guía, como señalasen, tras interpretar de modo erróneo a Ponz, Ceán Bermúdez o Viu.

En lo que se refiere a las características físicas, solo un detalle escapa a la concisa descripción de Santos Samaniego: el material en que están ejecutados los soportes. Resulta evidente que, aunque no lo explicite, todas las inscripciones por él tratadas corresponden a estelas funerarias realizadas en granito (con mucho el soporte epigráfico más común en la epigrafía cauriense) ${ }^{101}$ cinco de ellas completas (Inscripciones I, II, III, V y VI) y una de la que solo transmite la cabecera (Inscripción IV).

Pudiera parecer que Santos Samaniego presta escasa atención a los aspectos de índole textual, dado que ni comenta las lecturas, ni aporta traducciones. Sin embargo ello no le resta valor. Como hemos tenido oportunidad de ver, sus transcripciones son bastante certeras, de suerte que las que ofrece para sus Inscripciones II y III podrían permitir considerar el nombre Lacar(i)us como una lectura válida, como un antropónimo a mantener en el repertorio onomástico de la Lusitania, frente a las reservas manifestadas a este respecto por Abascal Palazón o Vallejo Ruiz. ${ }^{102}$ Igualmente, su lectura para HAE 2213 (Inscripción VI) se ha visto corroborada en fechas recientes, tras la recuperación de la pieza, mostrándose más correcta que la transmitida por Díaz Martos ya a mediados del siglo XX.

Y al margen de la posibilidad ya expresada de que Santos Samaniego pudiera haber constituido una fuente directa de Felipe L. Guerra (o haber bebido ambos de una misma fuente desconocida, al menos, para CIL II 770), debemos destacar, igualmente, que su testimonio constituiría, como ya se indicó, el más antiguo identificado hasta la fecha en relación a la existencia de los epígrafes correspondientes a CIL II 770, 771, 783, 788 y 790 (dependientes todos de Velázquez en el CIL), así como, obviamente, el más temprano documento referente a $H A E$ 2213. Su nombre y obra, prácticamente ignorados por cuantos investigadores han tratado sobre la epigrafía de Coria con posterioridad, deben ser, por todo ello, convenientemente reintegrados.

En definitiva, reivindicando la figura de Santos Samaniego esperamos haber aportado un granito más a la comprensión del patrimonio epigráfico cauriense, así como al entendimiento del pasado romano de esta localidad.

101 Siguiendo la clasificación tipológica realizada por Esteban Ortega (en CILCC IV) para los epígrafes de Coria, vemos que de las 87 inscripciones romanas de esta localidad contamos solo con tres aras, un árula, dos pedestales, cinco lápidas, una cupa, un miliario y dos textos funerarios de características inciertas (probablemente estelas). El resto de inscripciones de Coria, es decir, un total de 71, corresponden a estelas funerarias realizadas en granito, con mucho el material más usado en la epigrafía romana cauriense, en cuyo conjunto, y aunque este dato no puede precisarse para un total de cinco epígrafes perdidos, solo existen tres piezas realizadas en mármol.

102 Abascal Palazón 1994, 48; Vallejo Ruiz 2005, 493. 


\section{Referencias bibliográficas}

Abascal Palazón, J. M.

(1994): Los nombres personales en las inscripciones latinas de Hispania, Murcia.

(2012): "La Arqueología en los “viajes literarios" por España en tiempos de los Borbones", [en] M. Almagro-Gorbea (ed.), De Pompeya al Nuevo Mundo. La corona española y la arqueología en el siglo XVIII (=Real Academia de la Historia. Publicaciones del Gabinete de Antigüedades, Antiquaria Hispanica 23), Madrid, 2012, 53-69.

Abascal Palazón, J. M. - Cebrián Fernández, R. (2005): Manuscritos sobre antigüedades de la Real Academia de la Historia (=Real Academia de la Historia. Publicaciones del Gabinete de Antigüedades, Antiquaria Hispanica 12), Madrid.

Armistead, S. G. (1985): “Tres nuevas lápidas hispano-romanas de Coria (Cáceres)”, Archivo Español de Arqueología 58, 151-152.

Burkholder, M.A. (s.d.): "Bernardo Santos Calderón de la Barca”, [en] Diccionario Biográfico Electrónico, Real Academia de la Historia [http://www.dbe.rah.es/biografias/35574/ bernardo-santos-calderon-de-la-barca].

Canto, A. (1994): "Un precursor hispano del CIL en el siglo XVIII: el marqués de Valdeflores", Boletín de la Real Academia de la Historia 191, 499-516.

Ceán Bermúdez, J. A. (1832): Sumario de las antigüedades romanas que hay en España, Madrid.

Cerrillo Martín de Cáceres, E.

(2001-2002): "Epigrafía latina y transmisión de inscripciones en Cáceres entre los siglos XVIII y XIX. De los manuscritos de Boxoyo y Constanzo al CIL II de E. Hübner", [en] Soliferreum, Studia archaeologica et historica Emeterio Cuadrado Díaz ab amicis, collegis et discipulis dicata (=Anales de Prehistoria y Arqueología 17-18), Murcia, 495508.

(2007): Claudio Constanzo y la epigrafía extremeña del siglo XIX (=Real Academia de la Historia. Publicaciones del Gabinete de Antigüedades, Antiquaria Hispanica 16), Madrid.

(s.d.): “José de Viú y Moreu”, Diccionario Biográfico Electrónico [http://dbe.rah.es/ biografias/78383/jose-de-viu-y-moreu].

Corchón García, J. (1955): "Inscripciones cacereñas inéditas", Boletín de la Real Academia de la Historia 137, 119-132.

Coria, F. de (1608): Descripcion Historica y general de la Provincia de Extremadura, que contiene lo mas memorable, desde el principio de la Fé; fundacion de sus Yglesias y Obispados, con otras cosas de notar, Biblioteca Nacional de España, Ms. 23.044, [¿original?]; Fondo Antiguo de la Universidad de Valladolid, Ms. U/Bc Ms 079; Real Academia de la Historia, Ms. 9-5029.

Cornide, J. A.

(1798-1801a): Forner. Cauria oy Ciudad de Coria, Real Academia de la Historia, Ms. 9-3917-29.

(1798-1081b): Coria, Real Academia de la Historia, Ms. 9-3917-30.

Díaz Martos, A.

(1957): "Inscripción en Coria (Cáceres)", Revista de Estudios Extremeños 13, 346-348.

(1961): "Documentos epigráficos sobre la Coria romana", [en] Actas del VI Congreso Nacional de Arqueología (Oviedo, 1959), Zaragoza, 217-218.

Dorado, B. (1776): Compendio histórico de la ciudad de Salamanca, su antigüedad, la de su Santa Iglesia, su fundación y grandezas, Salamanca. 
Esteban Ortega, J. (2017): Corpus de inscripciones latinas de Cáceres. Vol. IV: Caurium, Cáceres (=CILCc IV).

Fernández Serrano, F. (1958): El médico don Felipe León Guerra y Cumbreño (1807-1890), escritor guadalupense, Guadalupe.

Fita, F.

(1882): Actas inéditas de siete concilios españoles celebrados desde el año 1282 hasta el de 1314, Madrid.

(1905): "Nuevas inscripciones romanas", Boletín de la Real Academia de la Historia 46, 76-81.

Gimeno Pascual, H.

(1993): "Appendix III: Manuscritos y epigrafía latina: datos para un censo español", [en] M. H. Crawford (ed.), Antonio Agustín. Between Renaissance and Counter-Reform, London, 291-302.

(1997): Historia de la investigación epigráfica en España en los siglos XVI y XVII a la luz del recuperado manuscrito del Conde de Guimera, Zaragoza.

Grupo Mérida (2003): Atlas Antroponímico de la Lusitania romana, Mérida-Bordeaux.

Guerra, F. L.

(1840): Lápidas romanas de la ciudad de Coria, copiadas y remitidas a la Academia de la Historia por Felipe Guerra desde Gata en 1840, Real Academia de la Historia, Ms. CC-9-3931-4/2.

(1865): Notas á las antigüedades de Extremadura de D. José Víu, Cáceres.

Hernando Sobrino, $\mathrm{M}^{\mathrm{a}} \mathrm{R}$.

(2009): Manuscritos de contenido epigráfico de la Biblioteca Nacional de Madrid (siglos XVI-XX): la transmisión de las inscripciones de la Hispania romana y visigoda, Madrid. (2017): Alejandro Javier Panel (1699-1764) y la epigrafia hispana. Un jesuita francés en el "infierno abreviado" (=Ausonius Éditions. Scripta Receptoria 11), Bordeaux.

Hurtado San Antonio, R. (1977): Corpus Provincial de Inscripciones Latinas de Cáceres, Cáceres $(=$ CPILC).

Hübner, E. (1869 y 1892): Corpus Inscriptionum Latinarum II. Inscriptiones Hispaniae Latinae, Berlin; Inscriptionum Hispaniae Latinarum Supplementum, Berlin (=CIL II).

Jiménez Navarro, E. (1949): "La colección de lápidas de don Claudio Constanzo. Un manuscrito arqueológico extremeño (1800)", Revista de Estudios Extremeños 5, 339-353.

Mantas, V. G. (2002): "Recensão a José Ignácio SAnchéz Albalá e Diego Vinagre Nevado, Corpus de Inscripciones Latinas de Coria, "Temas Caurienses" 1, Coria, 1998, 133 páginas, ilustrado", Conimbriga 41, 280-286.

Martín Valls, R. (1970): "Hallazgos procedentes de Coria", Boletín del Seminario de Estudios de Arte y Arqueología 36, 447-451.

Martínez, M. R. (1901): “Coria”, Revista de Extremadura 3, 343-357.

Mélida, J. R.

(1908): “Dos lápidas romanas en Coria", Boletín de la Real Academia de la Historia 52, 1-8. (1924): Catálogo Monumental de España. Provincia de Cáceres, Madrid.

Morán, C. (1945): "Nueva inscripción romana (Coria)”, Archivo Español de Arqueología 18, 89-90.

Muñoz y Romero, T. (1858): Diccionario bibliográfico-histórico de los antiguos reinos, provincias, ciudades, villas, iglesias y santuarios de España, Madrid.

Palomar Lapesa, M. (1957): La onomástica personal pre-latina de la antigua Lusitania: estudio lingüístico (=Publicaciones del Colegio Trilingüe de la Universidad de Salamanca. Theses et studia philologica Salmanticensia 10), Salamanca. 
Ponz, A. (1778): Viaje de España en que se da noticia de las cosas mas apreciables, y dignas de saberse, que hay en ella. Tomo VIII, Madrid.

Ramón y Fernández Oxea, J. (1955): "Nuevos epígrafes romanos en tierras de Cáceres", Boletín de la Real Academia de la Historia 136, 251-275.

Rodríguez Hernández, J. (1966): "Dos nuevas aras en Coria a dos divinidades gemelas", Zephyrus 17, 121-130.

Roldán, J. M. (1971): Iter ab Emerita Asturicam. El Camino de la Plata (=Universidad de Salamanca. Estudios Históricos y Geográficos 112), Salamanca.

Sánchez Albalá, J. I. - Vinagre Nevado, D. (1998): Corpus de las inscripciones latinas de Coria (=Temas caurienses 1), Coria (=ILC).

Santos Samaniego, A. (s. XVIII): Memorias para la Historia de la Santa Yglesia de Coria (y) Chronología de sus Obispos, Biblioteca Nacional de España, Ms. 13.078.

Saponi Sergio, M. J. (1988): Epigrafía hispano-latina del partido judicial de Coria, Tesina inédita, Universidad de Cáceres.

Thouvenot, R. (1940): "Note sur trois inscriptions Lusitaniennes", Revue des Études Anciennes 42, 529-531 (https://doi.org/10.3406/rea.1940.3136).

Vallejo Ruiz, J. Ma (2005): Antroponimia indígena de la Lusitania romana (=Veleia, Anejos, Serie minor 23), Vitoria-Gasteiz.

Velázquez de Velasco, L. J.

(1753a): Observaciones de viage de Extremadura y Andaluzia del S(eñ)or Velazquez con varios Cathalogos de Bibliothecas en que se hallan libros pertenecientes a la Historia de España. I. Provincia de Extremadura de Leon y p(ar)te del r(ein)o de Leon, Real Academia de la Historia, Ms. 9-4118-1.

(1753b): Informe a la Real Academia de la Historia sobre su viaje a Extremadura entre 1752 y 1753, Madrid, Real Academia de la Historia, Ms. CAG-9-7980-5/42 [transcripción y comentario de J. M. Abascal Palazón].

(1765): Noticia del viage de España hecho de orden del rey, y de una nueva historia general de la nación desde el tiempo mas remoto hasta el año de 1516 sacada únicamente de los Escritores y Monumentos originales y contemporáneos, con la colección universal de estos mismos Escritores y Monumentos recogidos en este viage, Madrid.

(2015): Viaje de las Antigüedades de España (1752-1765), (=Real Academia de la Historia. Publicaciones del Gabinete de Antigüedades, Antiquaria Hispanica 25, Manuscripta Antiquitatum 7), Madrid, II vols. [edición y estudio de J. Maier Allende, catálogo de dibujos y mapas de C. Manso].

Velo y Nieto, G. (1968): Castillos de Extremadura (tierra de conquistadores). Cáceres, $1^{a}$ parte, Madrid.

Viu, J. de (1852): Extremadura. Colección de sus inscripciones y monumentos, seguida de reflexiones importantes sobre lo pasado, lo presente y el porvenir de estas provincias, Madrid. 